\title{
Historical droughts manifest an abrupt shift to a wetter Tibetan Plateau
}

\author{
Yongwei Liu ${ }^{1}$, Yuanbo Liu ${ }^{1 *}$, Wen Wang ${ }^{2}$, Han Zhou ${ }^{3}$, Lide Tian ${ }^{4}$ \\ ${ }^{1}$ Key Laboratory of Watershed Geography Sciences, Nanjing Institute of Geography and Limnology, Chinese Academy of \\ Sciences, Nanjing, China \\ $5 \quad{ }^{2}$ State Key Laboratory of Hydrology-Water Resources and Hydraulic Engineering, Hohai University, Nanjing, China \\ ${ }^{3}$ Wuhan University of Technology, Wuhan, China, \\ ${ }^{4}$ Yunnan University, China \\ Correspondence to: Yuanbo Liu (ybliu@niglas.ac.cn)
}

\begin{abstract}
10 interactions between land and atmosphere. It experienced significant climate warming and spatially and temporally variant wetting over the past half century. Because of the importance of land surface status to the interactions, determining the wetting/drying of the TP from individual changes in precipitation (Prep) or temperature is difficult. Soil moisture (SM) is the water synthesis of the surface status. The persistent deficit of SM (SM drought) is more sensitive to climate change than normal SM. This study first explored the climate wetting/drying of the TP from variations in historical SM droughts over 15 1961-2014, with a focus on spatiotemporal patterns, long-term variations, and climate causes of summer (May-September) SM droughts based on multiple observation and reanalysis data. The results showed comparatively frequent and severe droughts in the central and southern regions, particularly in the semi-arid and sub-humid zones. SM drought exhibited an abrupt and significant $(\mathrm{p}<0.05)$ alleviation in the central TP in the mid-1990s. The prominent drought alleviation indicated a hydro-climate shift to a wetter plateau, not merely steady trends in the literature. We demonstrated that the wetting shift was

20 dominated by Prep over potential evapotranspiration (PET). By contrast, the in-phase trends before and after the shift were predominantly driven by the PET. Furthermore, the Prep dominance was largely attributed to a phase transition of the Atlantic multi-decadal oscillation from cold to warm, accompanied by a weakening westerly since the mid-1990s. The PET control on in-phase trends was realized through multiple climate control of temperature, radiation, and vapor pressure deficit. Regionally, the wetting shift was distinct from semi-arid to sub-humid, and from sub-humid to humid climate. Such 25 spatiotemporal changes may affect the TP's atmospheric circulation and, subsequently, the Asian monsoon and global circulation, in addition to fragile ecosystems in the TP.
\end{abstract}




\section{Introduction}

The Tibetan Plateau (TP), with an area of $\sim 2.5$ million square kilometers and more than half at the altitude above $4000 \mathrm{~m}$ in central Asia, is the highest and most extensive plateau in the world (Fig. 1). It therefore has long been described as "the roof of the world" and referred to by the scientific community as "the third pole". The TP and its surroundings contain the largest number of glaciers outside the polar regions and the largest concentration of inland lakes worldwide (Wan et al., 2016). It is also regarded as the "water tower of Asia", which is the birthplace of dozens of major rivers in Asia (e.g.,

35 Yangtze River, Huang River, Yarlung Zangbo River, Indus River, and Ganges). The TP exerts strong thermal forcing on the atmosphere (i.e., land-atmosphere feedback) over the Asian monsoon region (Yang et al., 2014). The climate change of the TP has profound impacts on the Asian and even global climate and hydrology.

The TP has undergone significant warming over the past decades (Liu and Chen, 2000; Yao et al., 2012). The air temperature (Temp) has increased by approximately $0.35{ }^{\circ} \mathrm{C}$ per decade since 1970 (Yao et al., 2019), at a warming rate of 1.5 times the global surface air temperature increase (Zhang et al., 2013; Wang et al., 2008). The magnitude of climate warming increases from south to north (Yang et al., 2011; You et al., 2016). As a consequence of the greenhouse effect along with the increased absorbed energy via the snow-albedo feedback (Liu and Chen, 2000) and cloud-radiation interactions (Duan and Xiao, 2015), the TP's warming is accelerated. The increasing Temp substantially affects the plateau's hydrological cycle, and the melting of glaciers, degradation of permafrost, increasing of river discharge, and expansion of lakes are among the most prominent effects of climate warming (Cheng and Wu, 2007; Yao et al., 2012; Cuo et al., 2014; Teng et al., 2021). The increasing Temp also increases the evaporative demand and consequently tends to contribute to the climate drying or aridity of the TP (Kuang and Jiao, 2016; Yao et al., 2019). Unlike the pronounced increase in Temp, the precipitation (Prep) did not show consistent, plateau-wide changes over the past decades (Yang et al., 2011). Although the majority of rain gauges and station measurements exhibited general increasing trends in Prep, the trends were variable in space and time with large heterogeneity (Yao et al., 2012; Kuang and Jiao, 2016). The Prep in the subregions is increasing (e.g., west and central TP) in some and decreasing (e.g., southeast TP) in others, accompanied by non-uniform changes in different seasons (Xie et al., 2010; Yang et al., 2011; Gao et al., 2014). Furthermore, the actual evapotranspiration (ET) generally follows the Prep changes under significant warming (Gao et al., 2007; Yin et al., 2013). Thus, the increase/decrease in Prep cannot effectively reflect the climate wetting/drying of the plateau. In the context of a significant overall warming up and a variant Prep increase/decrease in space and time, the wetting/drying changes in the TP become complicated and remain unclear.

Although Prep and Temp are the focus of climate change, they cannot directly and effectively reflect the climate wetting/drying of the TP. The TP is the region with the strongest land-atmosphere coupling in the mid-lattitudes (Xue et al., 2017), where both Prep and Temp are insufficient to account for the impacts of the feedback from the underlying land

60 surface to the atmosphere. Meanwhile, soil moisture (SM) is a pivotal link between the land surface and the atmosphere (Wanders et al., 2014). It is also the largest storage component of Prep and radiation anomalies on land (Seneviratne et al., 
2010). SM not only determines the allocation ratio of rainfall in surface flow and infiltration but also couples with evaporation and controls the water and energy feedback from the land surface to the atmosphere. Specifically, SM modulates temperature variability through evaporation cooling (i.e., SM-Temp coupling) and influences Prep through the impacts on evaporation and boundary layer thickness (i.e., SM-Prep coupling) (Koster et al., 2011). Therefore, SM changes (drying/wetting) not only affect the regional underlying incoming water and energy redistribution but also produce impacts on the large scale even global climate system (Koster et al., 2016). Moreover, SM anomalies can persist for months, with substantial impacts on water and energy fluxes on land. These properties makes SM capable of comprehensively reflecting climate anomalies and land surface feedback (Diro and Sushama, 2017). Compared with the abnormal high or normal SM status, the abnormal low SM status (i.e., SM deficiency/drought) is more sensitive to climate change, because the soil under low moisture status is more sensitive to Prep variation and has more control on evaportranspiration (Seneviratne et al., 2010). Hence, the SM deficiency (drought) with its variations could better reflect the climate wetting/drying of the TP under the coupled land and atmosphere (Lansu et al., 2020; Liu et al., 2021). However, according to our review of the literature, the climate wetting/drying of the TP has never been investigated from the perspective of variations in SM droughts. Little is known about the SM droughts of the TP, including not only the drought spatiotemporal patterns and long-term variations but also the climatic causes behind them.

Therefore, this study investigated the climate wetting/drying of the TP from the perspective of changes in historical SM droughts over the last half century. A synthetic investigation of SM droughts was conducted to (i) understand the spatiotemporal patterns and long-term variations in SM droughts on the TP and (ii) explore the climate causes behind them.

80 This study assessed the SM droughts in summer (May-September). This practice is to ensure the reliability of SM drought identification, because SM is frozen or freeze-thawed during cold months (i.e., October - next April) in the TP. Large-scale accurate, reliable SM estimation cannot be achieved with limited knowledge of the freeze-thaw processes for both remote sensing retrieval and land surface modelling (Taylor et al., 2012; Zwieback et al., 2015; Liu et al., 2019a).

\section{Study area and data}

\section{$85 \quad 2.1$ Study area}

TP is the largest plateau in China and the highest in the world (Fig. 1a). The plateau is dominated by the Indian monsoon and the westerlies, with limited influence from the East Asian monsoon (Yao et al., 2012; Yang et al., 2014). The climate presents a general characteristic of low air temperature (Temp), strong solar radiation, and large spatial and temporal variability of Prep (Xie and Zhu, 2013; Xu et al., 2008). Limited by low Temp, the vegetation over most TP generally grows

90 in summer (May-September) when the monthly average Temp is above $0^{\circ} \mathrm{C}$ (Fig. S1). Spatial patterns of the monthly average Prep, Temp, and SM for May-September are shown in Fig. 1b-d. 


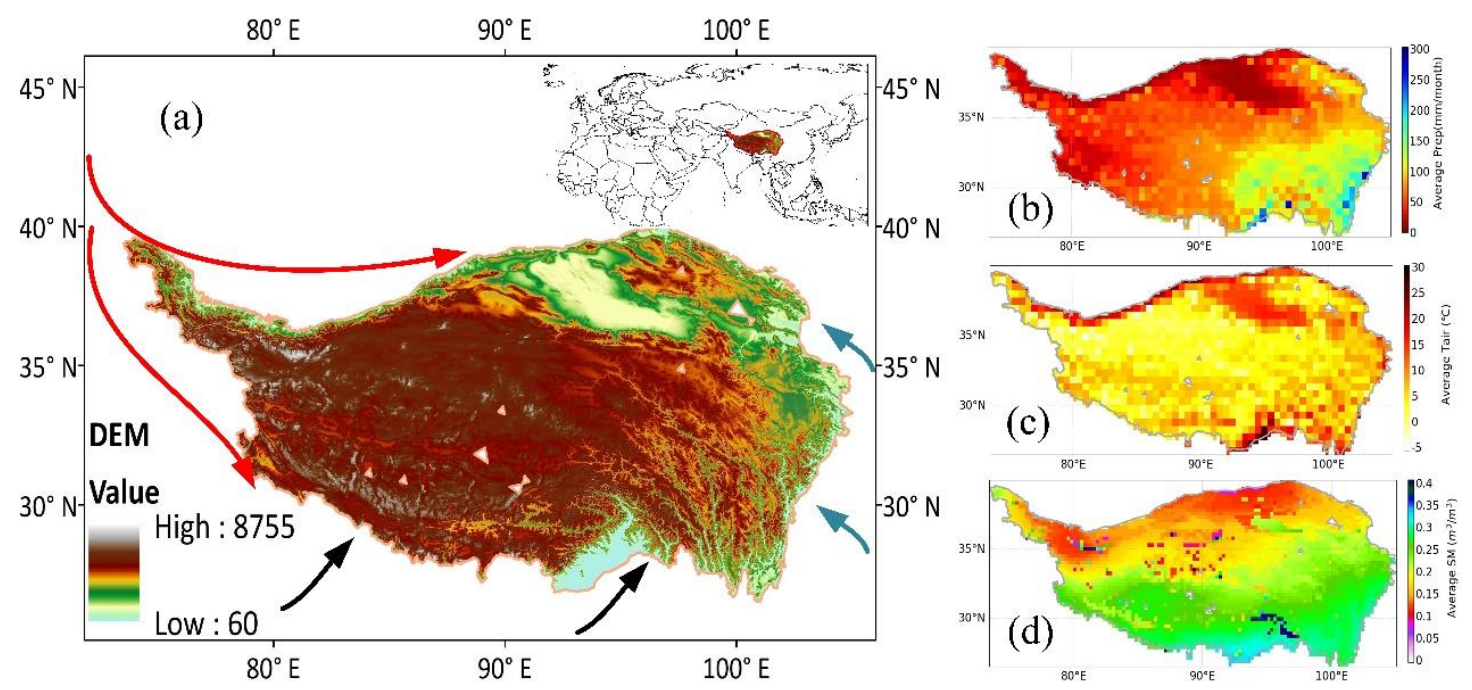

Figure 1. (a) Location of the Tibetan (TP) and the elevation; (b) Monthly average precipitation (Prep), (c) air temperature (Tair/Temp) and (d) soil moisture (SM) over the summer (May-September). Prep and Tair/Temp are based on the gauging interpolation data provided by the Chinese Meteorological Administration (CMA). SM is from the GLDASv2.0/Noah dataset with a depth of $0-10 \mathrm{~cm}$. The black, red, and blue arrows represent the Indian monsoon, the westerlies and the East Asian monsoon, respectively.

\subsection{Data}

The SM data generated by the Noah model driven by the Global Land Data Assimilation System (GLDASv2.0/Noah) were used in this study. This decision is based on a large number of literature assessing the data quality of the existing SM products (e.g., Su et al., 2011; Chen et al., 2013b; Zeng et al., 2015; Bi et al., 2016; Zhang et al., 2018, 2019a). Land surface models can successfully simulate the temporal variation in SM (Bi et al., 2016). The SM data of the TP simulated by the Noah model was proved to perform better than other datasets based on in situ observations, for example, the ESA CCI SM from the European Space Agency's Climate Change Initiative project, the second Modern Era Retrospective Analysis for Research and Applications, and the global atmospheric reanalysis product of ERA-Interim from the European Centre for Medium Range Weather Forecasts) (Zhang et al., 2019a). GLDASv2.0/Noah simulates SM at four depths with spatial and temporal resolutions of $0.25^{\circ}$ and $3 \mathrm{~h}$. In this study, the monthly surface (0-10 cm) SM over 1961-2014 was utilized.

In this SM drought study, multi-elemental data of precipitation (Prep), air temperature (Temp), potential evapotranspiration (PET), surface (10 m) wind speed, downward radiation (Radi), vapor pressure deficit (VPD), latent heat

110 flux, and net radiation flux were used. Prep and Temp were provided by the Chinese Meteorological Administration with a 1 -month and $0.5^{\circ}$ resolution. They were produced based on over 2400 national ground-based meteorological gauging stations by using spatial interpolation approaches with elevation effects considered. PET, wind speed, Radi, VPD, latent heat flux, and net radiation flux were obtained from the output and forcing datasets of GLDASv2.0/Noah (Beaudoing et al., 2019). 
PET, wind speed, and latent heat flux were directly extracted from the GLDASv2.0/Noah dataset. Downward radiation/net radiation flux is a combination of the downward/net short-wave and long-wave radiation of the GLDASv2.0/Noah forcing. VPD was calculated based on the specific humidity, surface pressure, and surface $(2 \mathrm{~m})$ air temperature from GLDASv2.0/Noah. GLDASv2.0/Noah was entirely forced by the Princeton meteorological forcing dataset (Sheffield et al., 2006). This dataset was constructed by combining a suite of global observation-based datasets with the National Centers for Environmental Prediction-National Center for Atmospheric Research (NCEP-NCAR) reanalysis. Specifically, the contributing datasets used in the development of the forcing dataset comprised the NCEP-NCAR reanalysis, Climate Research Unit, Global Precipitation Climatology Project, Tropical Rainfall Measuring Mission, and the National Aeronautics and Space Administration Langley Surface Radiation Budget Project. In addition, the climate indices of the Atlantic multidecadal oscillation (AMO) (http://www.psl.noaa.gov/data/timeseries/AMO/) and the Pacific Decadal Oscillation (PDO) (https://www.ncdc.noaa.gov/teleconnections/pdo/) from the National Oceanic and Atmosphere Administration (NOAA)Physical Sciences Laboratory and the NOAA-National Centers for Environmental Information (NCEI), and the monsoon circulation index of the Indian summer monsoon (ISM) (http://apdrc.soest.hawaii.edu/projects/monsoon/seasonalmonidx.html (Wang et al., 2001)) and the East Asian summer monsoon (EASM) (http://ljp.gcess.cn/dct/page/65540 (Li et al., 2002)) were utilized. The ERA5 (the fifth generation ECMWF reanalysis) geopotential and U-/V- components of wind data were adopted in the upper air analysis (https://cds.climate.copernicus.eu/cdsapp\#!/search?type=dataset).

\section{Methodology}

Drought is a sustained period of below-normal water availability (Tallaksen et al., 2004). It has a temporally slow accumulation and spatially continuous expansion process. With the deepening of drought understanding, drought identification has expanded from a single time dimension to space-time synchronous recognition (Andreadis et al., 2005; Lloyd-Hughes, 2012; Xu et al., 2015; Herrera-Estrada et al., 2017; Zhu et al., 2019). Space-time joint identification can consider the space-time continuous property of actual droughts and reconstruct the drought development process. Therefore, it could improve the reflection of the real characteristics of droughts (e.g., the spatial position/overall severity/duration of drought) and benefit the investigation of the climate forces that drive behind droughts (Lloyd-Hughes, 2012; Liu et al., 2021). In this study, the space-time joint identification of droughts was realized by recognizing the drought clusters (the spatially continuous regions under drought at 1 month) and eventually the drought events (the spatially continuous and temporally overlapped domain under drought).

\subsection{Drought event identification}

The space-time joint identification of drought events comprises the following steps:

(1) Identification of drought conditions for each SM grid pixel. The percentile was used as the drought indicator because of its effectiveness in many large-scale drought assessments (e.g., Herrera-Estrada et al., 2017). The monthly SM 
percentile on each grid was calculated from the empirical cumulative distribution function of each month (May-September), separately based on the monthly SM from 1961 to 2014. Next, the monthly map of the SM percentile was smoothed using a 2-dimensional median filter to reduce the spatial noise. Grids with an SM percentile less than 0.15 are regarded as being under drought, because it approximates the common drought metrics of the standard precipitation index value of -1.0 (Guttman, 1999).

(2) Determination of the spatial continuity of grid pixels under drought. The spatially continuous grids below the drought threshold belong to one drought cluster. Drought clusters were identified using a spatial clustering method (Andreadis et al., 2005). Small clusters of less than 1.5\% of the TP area are not accounted for in case of spurious long droughts caused by tenuous spatial continuity (Liu et al., 2019b; Liu et al., 2021).

(3) Recognition of the temporal continuity of drought clusters. The temporal links of drought clusters between adjacent months were determined according to their overlapping areas. Drought clusters with overlapping areas over $625 \mathrm{~km}^{2}$ (i.e., one grid pixel) were classified as being in the same drought event (Herrera-Estrada et al., 2017; Liu et al., 2021).

\subsection{Drought characterization}

The following drought characteristics are accounted for in the space-time joint identification of drought events in a 3dimensional (latitude-longitude-time, 3-D) domain.

(1) Drought duration: the time interval between the onset and the ending of one drought event.

(2) Drought area: the total area affected by a drought in its duration.

(3) Drought intensity and severity reflect the strength of drought and the water deficiency of one drought event, respectively. Drought intensity is represented by the value of 1.0-percentile for each grid pixel (Herrera-Estrada et al., 2017), and for each drought cluster, drought intensity is characterized by the area average intensity of all grids within the drought cluster. Drought severity can be expressed as the cumulative value of drought intensity for all grids within the spacetime continuous structure of one drought event.

(4) Drought cluster/event centroid: being defined as the weighted center of the grid intensity with the intensity value at each grid within the drought cluster/event domain as weights. For more details on the aforementioned drought identification and characterization, please refer to our prior research (Liu et al., 2021).

\section{Results}

\subsection{Spatiotemporal patterns of soil moisture droughts}

Based on the space-time joint identification approach, 197 drought events (consisting of 350 drought clusters) were identified on the TP, which occurred in summer (May-September) from 1961 to 2014. For the identified drought events, drought duration varies from 1 to 5 months, drought area from 0.38 to $19.2\left(\times 10^{5}\right) \mathrm{km}^{2}$, and drought severity from 53.89 to 6275.99. Drought area and severity increased synergistically with the increase in drought duration (Fig. S2). Spatially, the 
accumulated drought duration, severity, and frequency (represented by the number of drought events) presented similar spatial patterns (Fig. 2). Extensive regions, particularly the central and southern TP, endured long-lasting (>30 months), comparatively severe (>30), and frequent (>25 events) drought situations over 1961-2014.

To obtain specific knowledge of each identified drought, we present an overview of the drought clusters by their location, area, and intensity in Fig. 3. Most TP experienced SM droughts with varying intensities. Large-scale drought clusters are mainly concentrated in the semi-arid and sub-humid regions, that is, the wet-dry transition zone (Fig. S3). Although the space-time joint identification could reshape the development process of drought, all 197 drought events with their spatiotemporal dynamic patterns can hardly be explicitly presented one by one. In this case, the most severe drought event is displayed in the 3-D domain as an example (Fig. 4a). Moreover, the standard anomaly of two predominant SM controlling factors in the hydrological cycle, that is, Prep and PET, are also present to illustrate their driving forces on SM drought (Fig. 4b, c). The Prep and PET monthly anomaly maps were observed 1 month before the drought occurrence, considering the time-delaying impacts of Prep and PET on SM drought (Van Loon and Van Lanen, 2012). This drought started in May 1994 in the northwest of the TP, with an area of 16\% of the TP. After 1 month growing in place, the drought cluster expanded to the southeast in July, and the drought area increased to 52\% of the TP. Next, the large drought cluster

190 split into two clusters (small in the north and large in the south) in August, which lasted until September, with 35\% of the TP area still under drought before the freezing season. Over the 5-month duration, it swept over 73\% of TP (basemap in Fig. 4b and c) and became the most serious drought over 1961-2014. The initial SM drought was co-driven by the persistent negative Prep anomaly and strong PET in April. Under an arid climate in the northwestern TP, the ET was limited by SM. The abnormal drying SM will induce an abnormally low ET and a high surface temperature increase by enhancing the 195 sensible heat flux outcoming. This feedback process aggravates the drought situation. Thus, the drought cluster grew in place until June. The southeastward expansion of drought was synergistically promoted by Prep and PET as both with significant anomalies occurring in June and July. Likewise, the drought persistence in August and September was contributed by the negative Prep anomaly combined with the strong PET capacity, particularly for the large part in the south. 

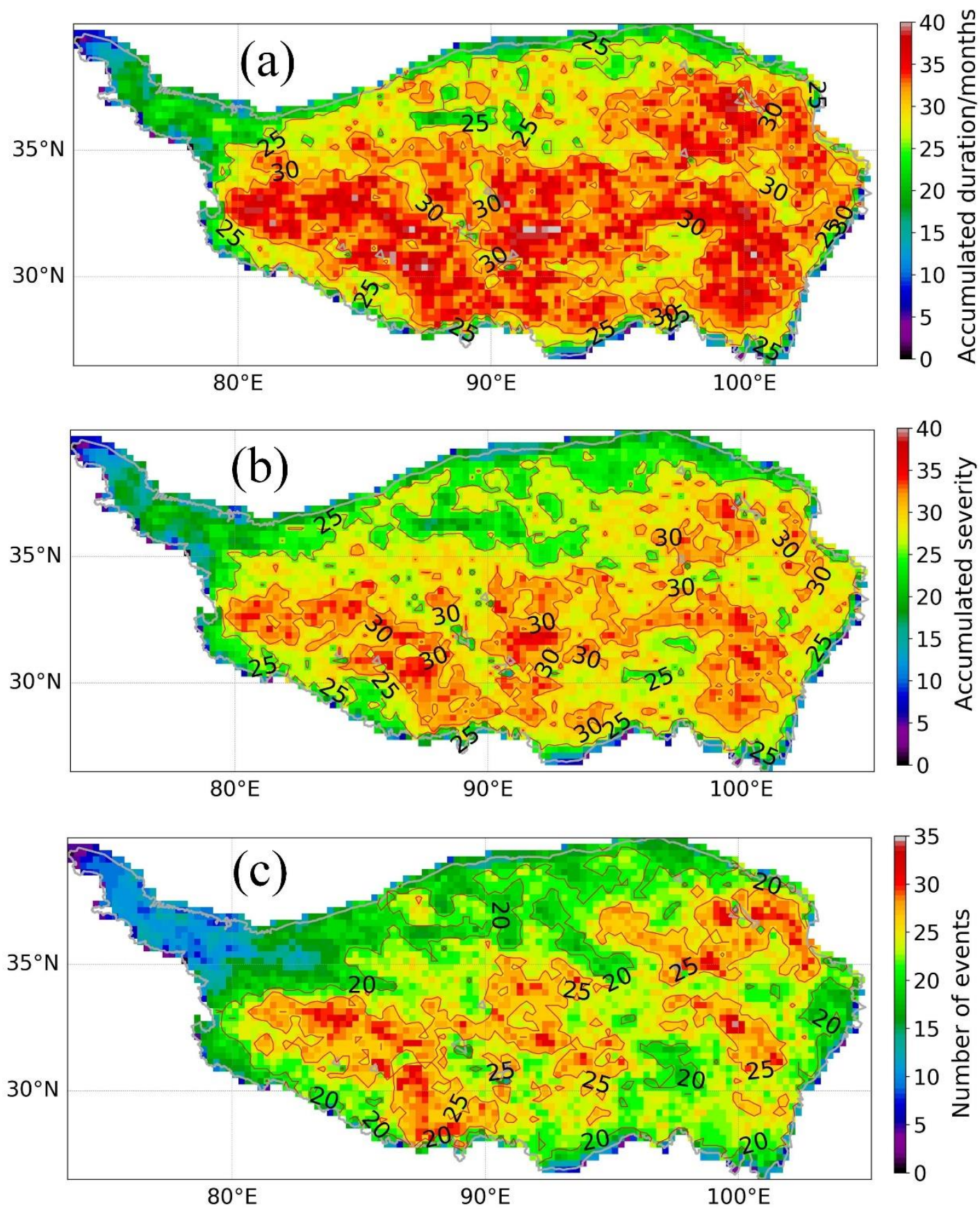

200 Figure 2. Spatial distribution of the accumulated drought duration (a), severity (b), and number of events (c) for the identified soil moisture drought events in summer (May-September) over 1961-2014 in a joint space-time perspective. 
https://doi.org/10.5194/hess-2022-28

Preprint. Discussion started: 3 February 2022

(c) Author(s) 2022. CC BY 4.0 License.

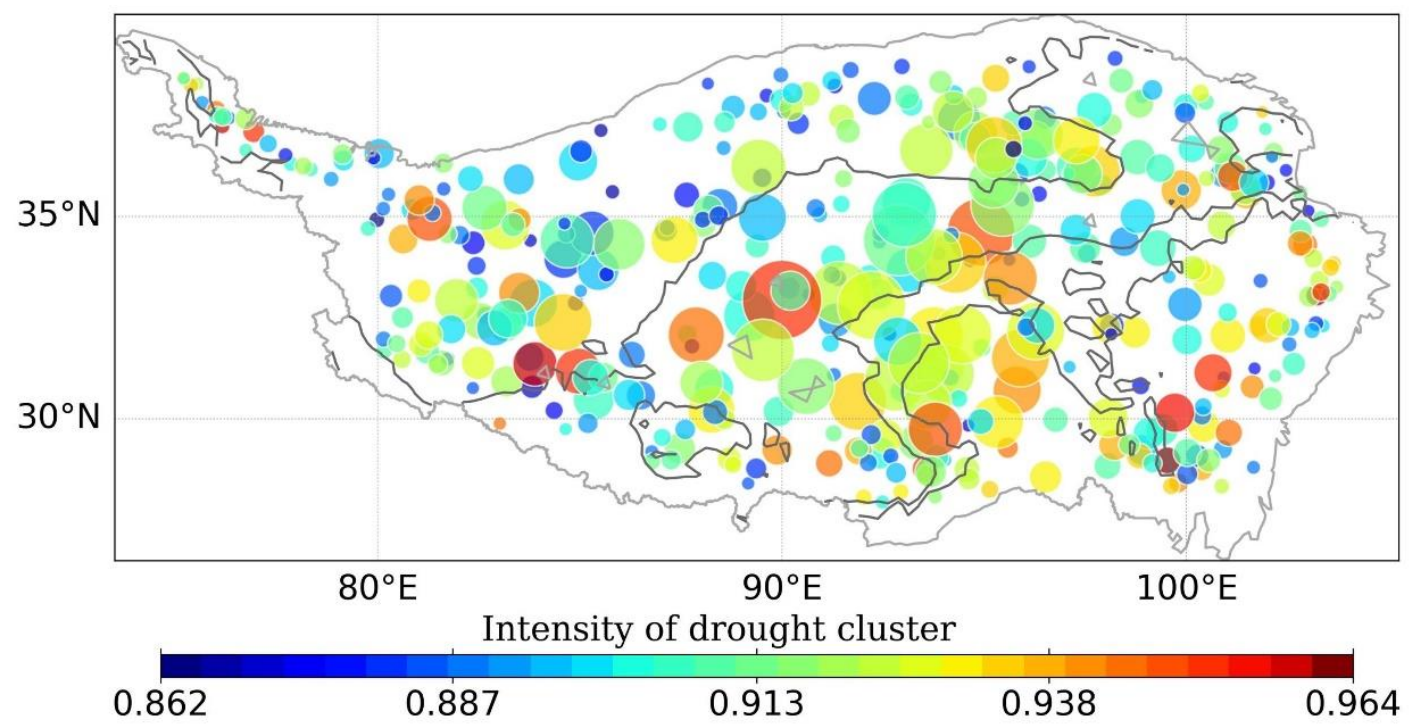

205 Figure 3. Map of the soil moisture drought clusters. The circle center and size represent the centroid and area of the drought cluster, respectively. The dimgray lines are the dividing lines between different climate zones (the same to Figure S3). 
https://doi.org/10.5194/hess-2022-28

Preprint. Discussion started: 3 February 2022

(c) Author(s) 2022. CC BY 4.0 License.
Hydrology and Earth System Sciences

Discussions

(a) Drought Event199405 199409
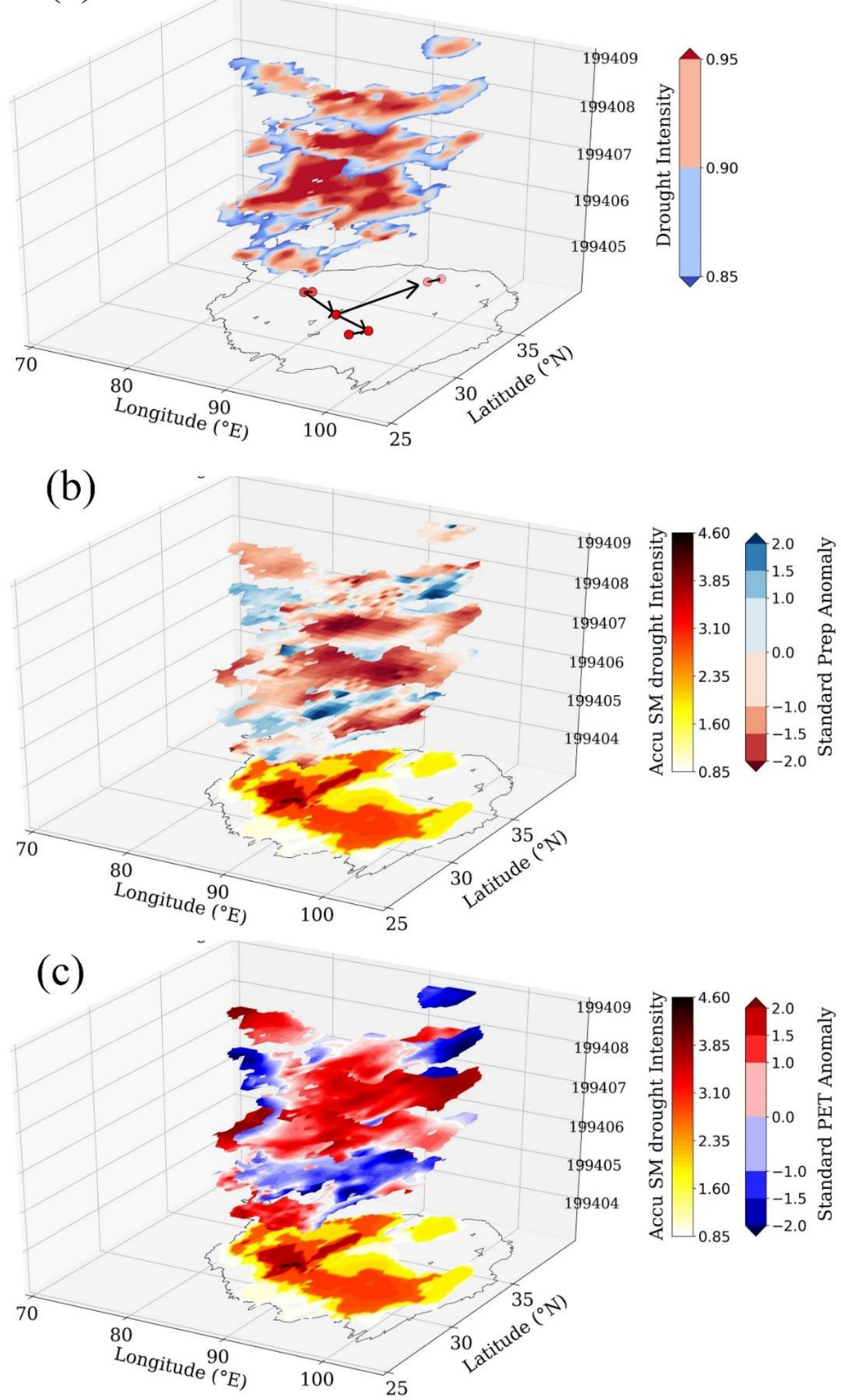
Figure 4. Spatiotemporal dynamic patterns of the most severe SM drought event over 1961-2014 (a), and the monthly standard anomaly maps of Prep (b) and PET (c) before (1 month) and during the drought duration over the drought cluster affected area. In (a), the red dots are the centroids of the drought clusters. The black arrow lines show the moving/expanding direction and trajectory of the drought clusters.

\subsection{Long-term variations in soil moisture droughts}

For the entire TP, SM droughts occurred almost every year over 1961-2014 (Fig. S4). However, annual drought showed a significant shift in drought severity (Fig. 5a). The abrupt shift occurred in 1995 (i.e., mid-1990s), with the maximum probability according to Pettitt diagnosis (Pettitt, 1979) (Fig. S5). The SM drought has had an abrupt, substantial alleviation since the mid-1990s. The drought tendency changed from a slight alleviating (before mid-1990s) to an un-ignored enhancing trend (after mid-1990s). For further insight into SM drought variations, the two predominant controlling factors of SM dynamics, that is, Prep and PET, were incorporated. Prep showed an abrupt, substantial increase after 1995, and the change in PET was nonsignificant (Fig. 5 b, c). This indicates that Prep likely dominated the wetting shift of SM. This is also supported by the significant and relatively higher correlation between the annual SM drought severity and Prep (partial correlation $r=-0.6)$ than PET $(r=0.48)$. Nevertheless, the enhancing SM drought after mid-1990s should be the effect of the increasing PET, because the rising Prep would adversely alleviate the drying tendency. The partial correlation statistics also illustrate that the SM drought trend after the mid-1990s is controlled by PET because $r=0.59$ with $p<0.05$ for PET and $r=$ -0.37 with $p>0.05$ for Prep, and the trend before the mid-1990s is affected by both Prep and PET because $r=-0.48$ with $p<$ 0.05 for PET and $r=0.53$ with $p<0.05$ for Prep. 

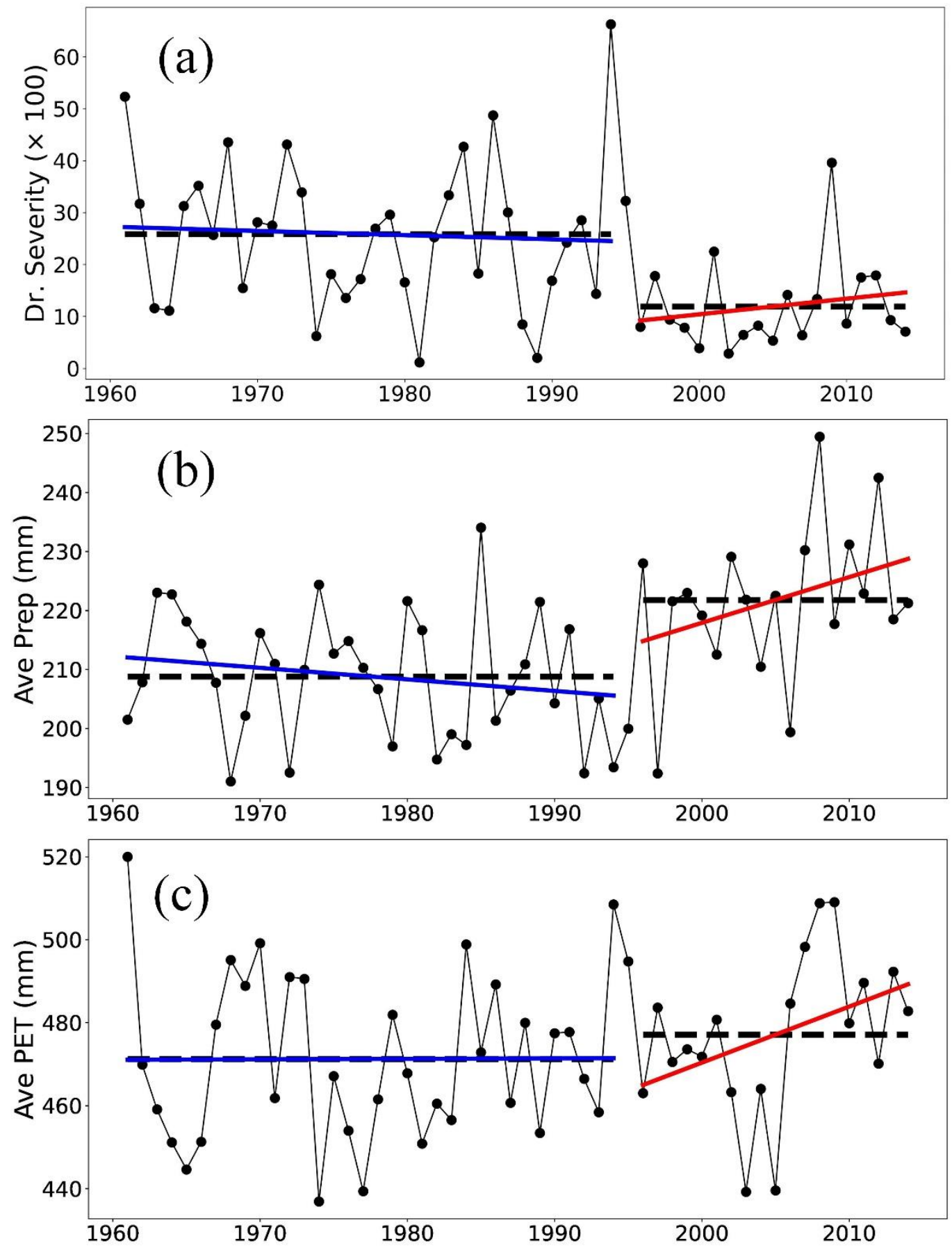

Figure 5. Variations of the (a) total annual SM drought severity, (b) yearly average precipitation (Prep), and (c) potential evapotranspiration (PET) over summer periods (May-September) from 1961 to 2014. The dotted black lines are the mean 
values over the periods of 1961-1994 and 1995-2014. The blue and red lines indicate the trend statistics for the period of 1961-1994 and 1995-2014, respectively.

For acquiring specific knowledge of the wetting shift of SM drought in space, the difference between the mean SM percentile after and before mid-1990s are considered, together with Prep and PET (Fig. 6). The drought decrease (indicated by the increased SM percentile) occurs in most ( $\sim 87 \%)$ of the TP, and the drought increase is in small parts $(\sim 13 \%)$ of the edge-region (Fig. 6a). The major wetting shift toward drought alleviation is mainly distributed in central TP (black rectangle in Fig. 6a), particularly for the semi-arid and sub-humid regions (Fig. S6, S3). The robust enhancement of SM drought is prevalent in a small part of the southeast TP (red rectangle in Fig.6a) with a humid climate (Fig. S6, S3). The aforementioned shift variations in SM drought are supported by the specific droughts identified under the space-time continuous framework, because the SM drought clusters had substantial reduction for most of the TP, merely with increased droughts in the southeast TP after the mid-1990s (Fig. S7). In addition, the rapidly expanded lakes in the central plateau after the mid-1990s and the substantial overall greening plateau are strong evidence of the wetting shift (Yang et al., 2014; Teng et al., 2021).

The wetting shift of SM in the central TP is likely due to the significant increase (>10 $\mathrm{mm}$ on average) in Prep in the central-west, and the joint increase in Prep and decrease in PET in the central-east (black rectangle in Fig. 6b and c). For the central TP with an arid, semi-arid, and sub-humid climate, SM strongly constrains ET variability. The large-scale significant 245 wetting shift of SM tends to accelerate the wetting and slow the warming up of the climate of the TP by increasing the ET and decreasing the surface air temperature. The wetting shift may also produce impacts on atmospheric circulation over the TP via land-atmosphere coupling. In addition, the robust enhancement of SM drought in the southeastern TP is likely promoted in collaboration by the significant decline in Prep and the substantial increase in PET (red rectangle in Fig. 6b, c). The synergistically abrupt change in Prep and PET toward dryness may pose risks to the transition of the long-term climate 250 state of this region. 

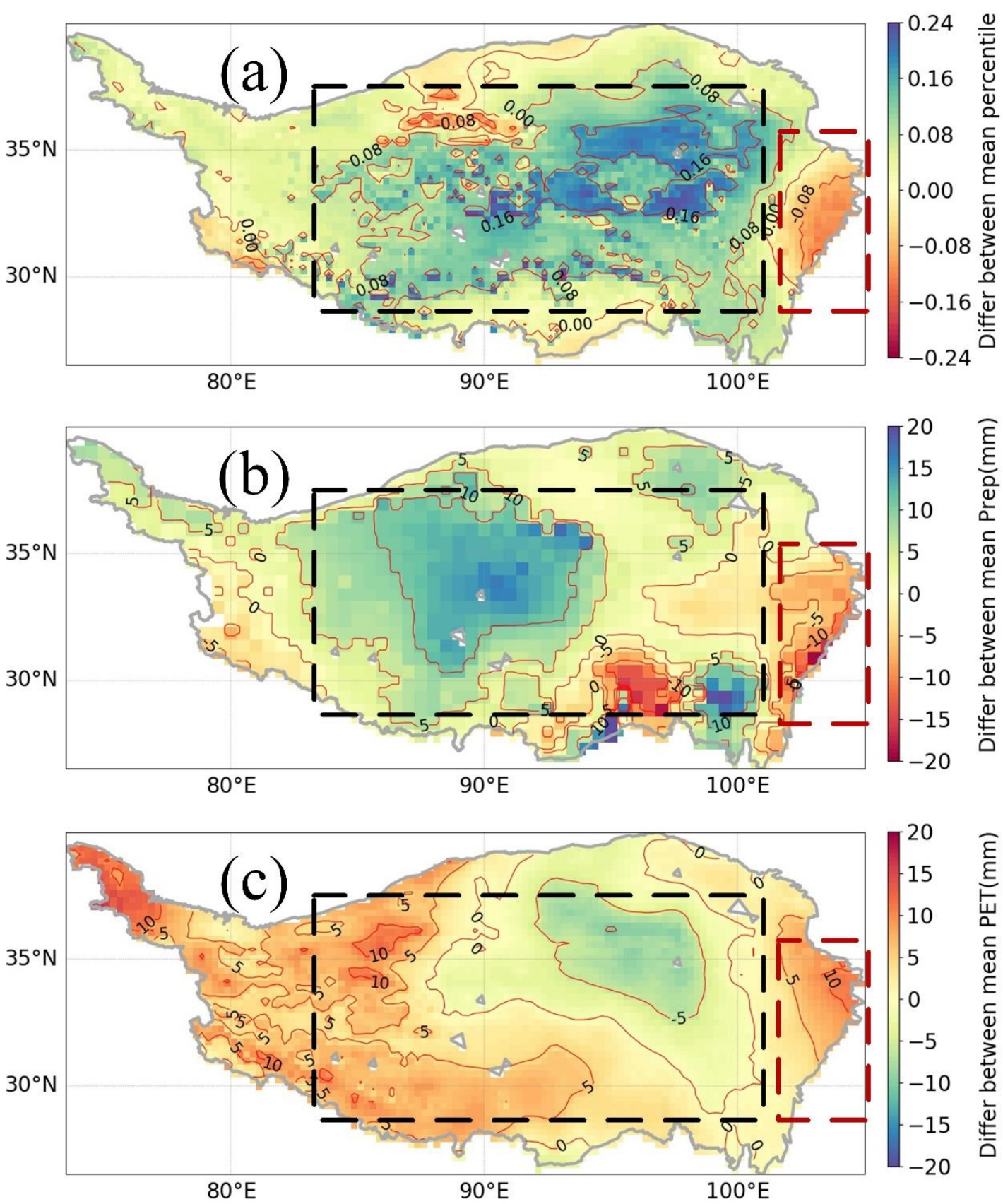

Figure 6. Difference (Differ) of the average state of the SM drought (a), mean Prep (b), and mean PET (c) between the periods after and before mid-1990s.

After the abrupt wetting shift in mid-1990s, the correlation between SM drought and Prep anomaly decreased for most 255 areas east of $\sim 90^{\circ}$ E. Comparatively, the correlation with PET increased, particularly for the northeast part (Fig. 7). However, 
the correlation with Prep increased but with PET decreased in regions west of $\sim 90^{\circ} \mathrm{E}$. This suggests that after the shift in SM, the Prep (i.e., water) controlling capacity for variations of SM drought was significantly weakened, while the PET (i.e., energy) control was intensified east of $\sim 90^{\circ} \mathrm{E}$. By contrast, west of $\sim 90^{\circ} \mathrm{E}$, the dominant capability of energy for $\mathrm{SM}$ dynamics was reduced, and the driving power of water was enhanced. This phenomenon may indicate a climate regime changing tendency of wetting over the TP.

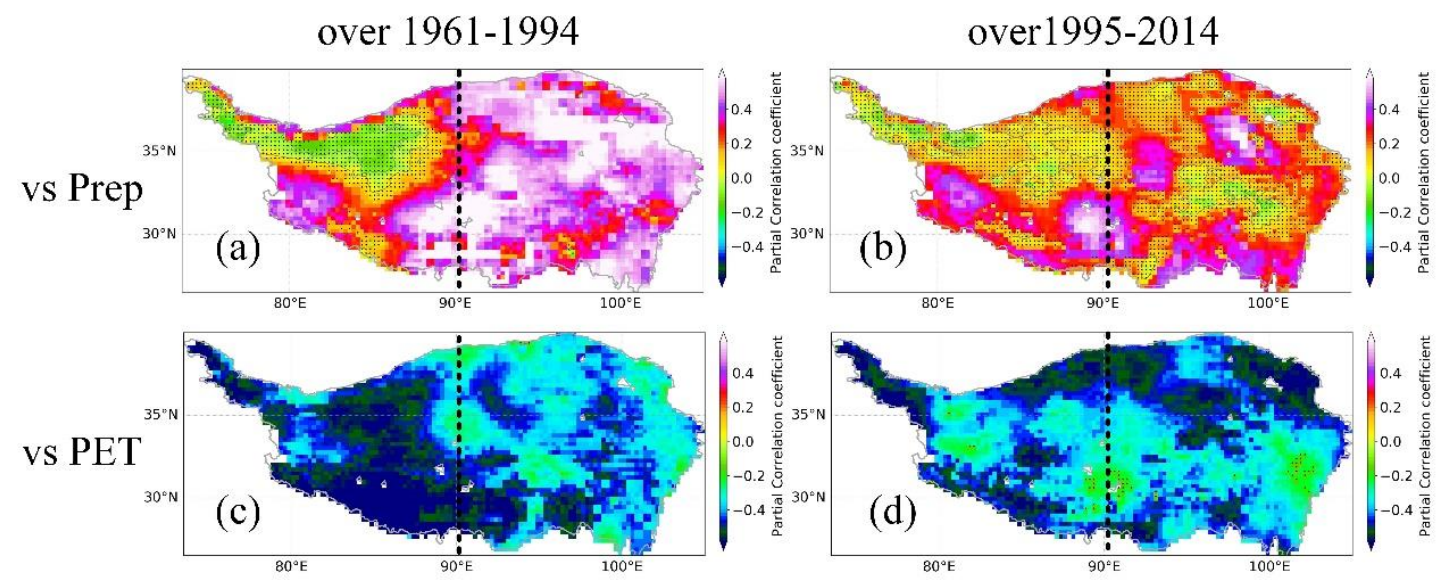

Figure 7. Spatial distribution of the partial correlation coefficient between the soil moisture (SM) percentile and the precipitation (Prep)/potential evapotranspiration (PET) anomaly over 1961-1994 and 1995-2014. The black dots denote the un-significant $(\mathrm{p}>0.05)$ correlations.

Due to the wetting shift and the associated water/energy control adjustment, the trend characteristic of SM drought was analyzed separately before and after the shift. Generally, SM drought is increasing (with decreasing SM percentile) in the southwest half of the TP, and decreasing in the northeast half for both stages (Fig. 8a, b). The later stage presents more evident drying/wetting trends with a larger magnitude of SM variations and an expanded area with significant changes than the prior stage. This feature seems to be the same for Prep and PET. The drying trends of the west TP (red rectangle) are dominated by PET, which is more obvious in the later stage because the drying tendency of SM is more significant under the power of PET drying although accompanied by Prep wetting (Fig. 8 b, d, f). This is also supported by the significant ( $p<$ $0.05)$ and high correlations of SM with PET, but the un-significant $(p>0.05)$ and low correlations with Prep in west TP (Fig. 7). The significant drying trends in the south-east TP (emerald rectangle) are likely controlled by Prep and PET in collaboration, because the drying trend patterns also present in Prep and PET for both stages and the SM percentile has significant and high correlations with Prep and PET (Fig. 7). In addition, the wetting trends in the northeast half are likely contributed by Prep and PET. We observed that the contribution of PET increased while that of Prep decreased after the shift, because SM has become more closely correlated with PET but less with Prep in the northeast part since mid-1990s (Fig. 7). 


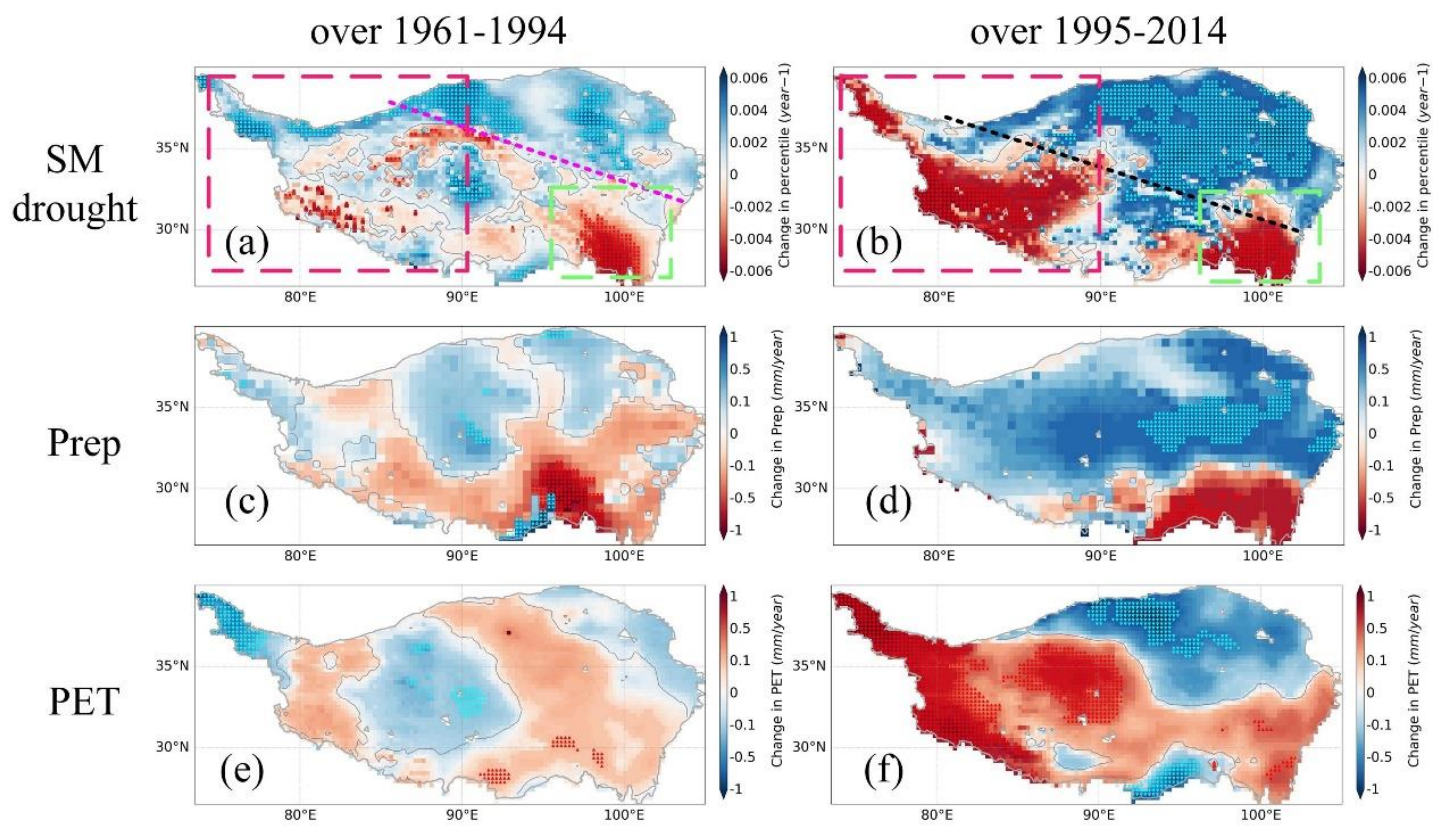

Figure 8. Spatial distribution of the trends in soil moisture (SM) percentile, precipitation (Prep), and potential evapotranspiration (PET) over 1961-1994 and 1995-2014. Note that the $\Delta / \nabla$ with cyan/red denote the significant $(\mathrm{p}<0.05)$ increasing/decreasing trends.

\section{Discussion}

\subsection{Possible linkages to the soil moisture drought shift}

The SM droughts of the TP in summer (May-September) had a significant shift of alleviation in the mid-1990s. Our results demonstrated that Prep was the primary driver of/contributor to the shift, and PET was the secondary. Prep variability on an inter-annual scale for summer TP is controlled by remote moisture transport driven by the general circulation of the atmosphere (Wang et al., 2017; Li Ying et al., 2019). In summer, the TP is mainly under the control of the ISM and westerlies, with limited influence from the EASM (Yao et al., 2012). For the westerly jet stream, its position and strength can be reflected by the AMO because of their high correlations on the inter-decadal scale (Sun et al., 2020). The ISM and EASM, with their strength, can be largely manifested in the PDO because both are significantly $(p<0.05)$ correlated with the PDO on the chronological scale.

Fig. 9 (a) shows that the AMO has experienced a phase transition from cold/negative to warm/positive since the mid1990s, both for the whole year and the summer cases. In the warm phase, the AMO would induce a wave train of cyclonic and anticyclonic anomalies over Eurasia in summer (Fig.10). These anticyclonic anomalies to the east of the TP tend to cause east wind anomalies, that is, the weakening of the westerly winds at 200hPa near the TP (Fig.10, gray rectangle). The 
weakened westerlies would reduce the water vapor transport beyond the eastern TP boundary and facilitate the convergence of water vapor (i.e., Prep formation) over the central TP (Wang et al., 2017; Zhou et al., 2019). The more the moisture gathered, the more the Prep falls in this region. At the same time, the abnomal cyclone to the west of the TP promoted the northward and eastward water vapor transport imported from the southwest boundary of the TP (Fig. 10, the green rectangle), which also increased the wetting shift of the central TP (Zhang et al., 2019b; Sun et al., 2020). In addition, our results suggested that the wetting shift in the central-eastern TP was partly due to PET declination (Fig.6c). The PET contribution probably benefited from the reduced wind speed (wind stilling) (Fig. S8). This result is also supported by the literature (e.g., Zhang et al., 2009; Yang et al., 2014).

Fig. 9 (b) shows that there was also a phase transition of the PDO from cold to warm in the mid-1980s. The ISM and EASM tend to be weakened due to the weakened land-sea thermal contrast in the warm phase (Li et al., 2010; Zhang and Zhou, 2015). Fig. 11a and b show that the ISM and EASM had a certain degree of weakening after the mid-1990s, which is supported by the decline in wind speed over the plateau (Fig. S8c). The two weakened monsoons are inclined to decrease the water vapor entering the TP from the southern and southeastern boundaries. Thus, they probably result in the decrease in Prep in near boundary regions and contribute to the robust enhancement of SM drought over the southeastern TP (Fig. 6a and b). Additionally, our results show that the abrupt drought enhancement in the southeastern TP is also promoted by PET, which actually benefited from the synthetic impacts of the substantially increased Temp, radiation, and VPD, and the reduced wind speed under a warming climate (Fig. S8).

Overall, the shift variation in SM drought is likely predominantly driven by the phase transition of the AMO from cold to warm since the mid-1990s. It should also be related to the phase transition of the PDO and the accompanying weakening of the ISM and EASM. Additionally, wind stilling continues to contribute to the shift variations in SM drought.
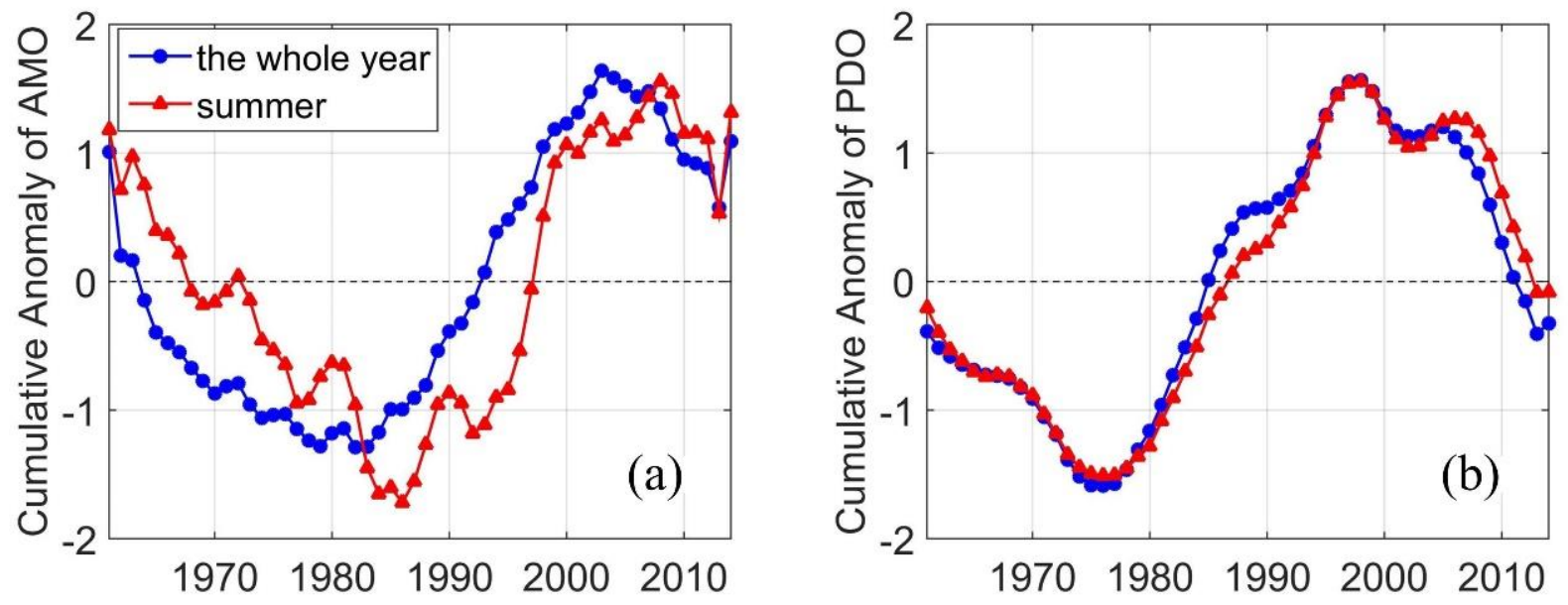

Figure 9. Variation of the cumulative anomaly of AMO and PDO both for the whole year and for summer cases. Note that the calculation of the cumulative anomaly statistics is referenced from Sun et al., 2020. 


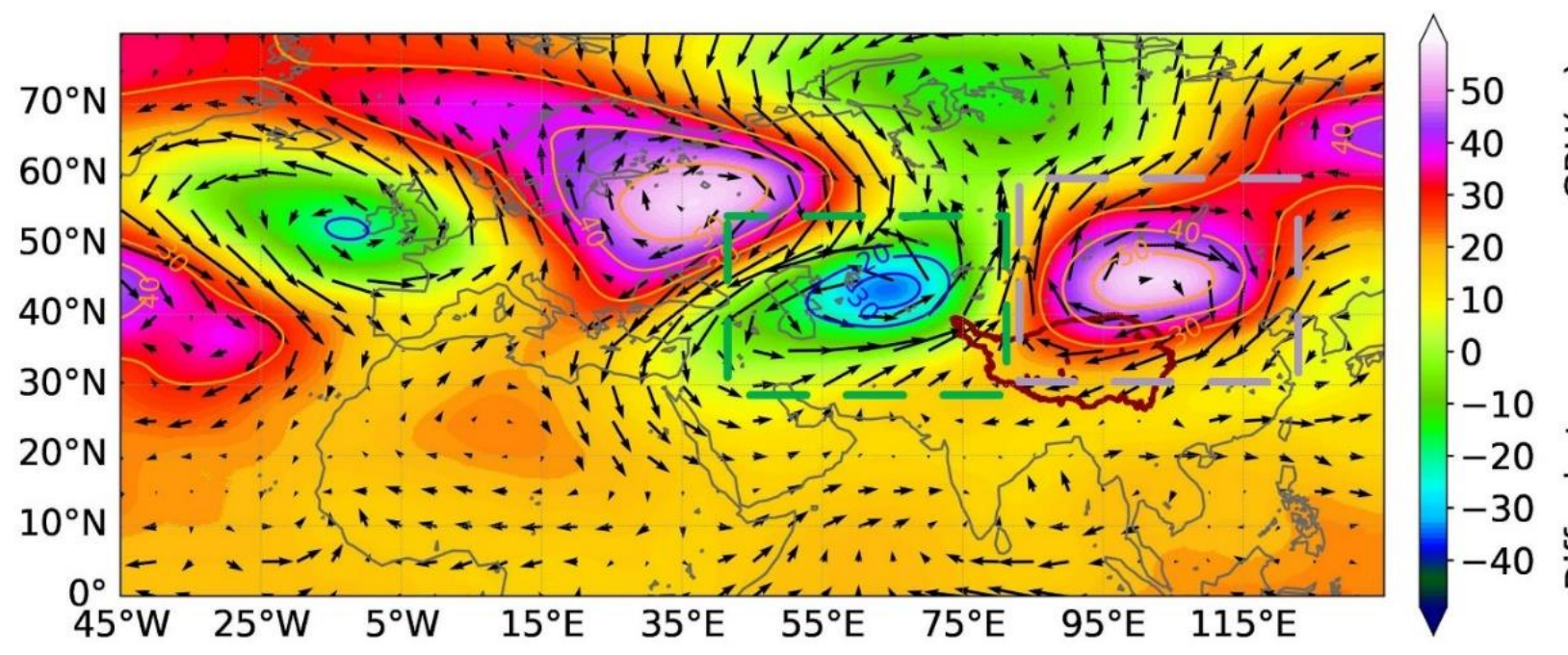

Figure 10. Differences (Differ) in summer (July) geopotential height (GPH) at $200 \mathrm{hPa}$ between the warm (1995-2014) and cold (1961-1994) phases of the AMO (the later stage minus the former stage). The bold red line represents the border of the TP.
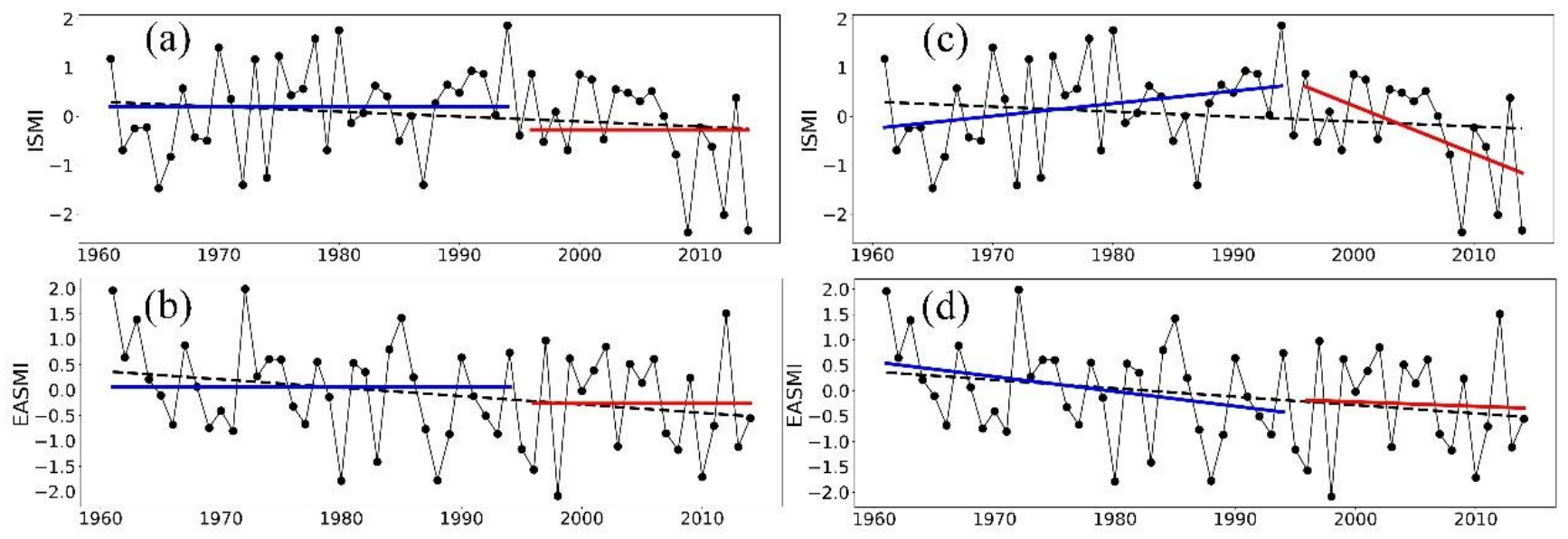

Figure 11. Variations of the Indian summer monsoon index (ISMI) and the East Asian summer monsoon index (EASMI) for June-July-August (JJA) over 1961-2014. (a), (b) are the period average state, and (c), (d) are the trends for 1961-1994 and 1995-2014, respectively. Both the period average value and the trends are denoted by the blue and red lines.

\subsection{Potential drivers for the spatial pattern of drought trends}

Due to the abrupt wetting shift of SM in the mid-1990s, its water and energy control capability had substantial changes in space over the plateau. The SM drought trends presented differences before and after the shift, with more significant trends in the later stage. We demonstrated that the significant drying SM after mid-1990 in the western TP was dominated by 
the increasing PET, and that in the south-eastern TP was a combined effect of the increasing PET and decreasing Prep (Fig. 8). The increasing trend of PET after the mid-1990s is supported by the literature (e.g., Yin et al., 2013 and Li et al., 2014). The increasing PET is probably contributed by the increasing Temp, Radi, and VPD in west TP, and a comprehensive effect of the increasing Temp, Radi, Wind speed, and VPD in the south-east (Fig. S9). The Temp increase is pronounced for the TP. Wind speed and VPD increase after the mid-1990s are also supported (Yin et al., 2013; You et al., 2014; Xie et al., 2015). In addition, the decreasing Prep in the south-east is related to the significant weakening of the ISM after the mid-1990s (Fig. 11c). The significant weakening of the ISM may decrease the water exchange between the Asian monsoon region and the plateau (Yang et al., 2014). Thus, this phenomenon led to less Prep and drying SM in the ISM affected south-east region (Fig. $8 \mathrm{~b}, \mathrm{~d})$. In addition, the significant wetting of SM in the northeast TP was synergistically controlled by increasing Prep and decreasing PET (Section 4.2). The Prep increase is related to the positive westerly wind anomalies over the entrance of the East Asia westerly jet in the upper troposphere and the strengthened northward water vapor transport from the south and east (Wang et al., 2018; Zhang et al., 2019b). The PET decrease seems to result from the decline in wind speed, Radi, and VPD (Fig. S9). Wind stilling is considered to be the factor with more importance (Zhang et al., 2009).

Overall, the enhanced drying tendency in the western TP (west of $\sim 90^{\circ} \mathrm{E}$ ) is primarily controlled by energy factors, that is, air temperature, downward radiation, and vapor pressure deficit. However, the significant drying (south-eastern TP) and the substantial wetting (northeastern TP) in east of $\sim 90^{\circ} \mathrm{E}$ is driven by not only energy but also the water variation dominated by the weakening monsoon of the ISM under global warming.

\subsection{Implications of the abrupt wetting shift of SM on TP climate}

The central TP experienced an abrupt wetting shift in SM over summer (May-September) in the mid-1990s, particularly for the semi-arid and sub-humid zones. The SM is generally dominated by water and energy from the atmosphere. At the same time, as the largest storage component of Prep and radiation anomalies on land, SM also controls the water and energy feedback from the land surface to the atmosphere by coupling with ET. The shift variations in SM tend to produce changes to the local/regional underlying incoming water and energy redistribution, that is, changes in the SM regime (Koster et al., 2016).

The SM regime is often distinguished based on the sensitivity of evaporation to SM change, which can be reflected in the relationship between SM and evaporative ratio (the fraction of latent heat in net radiation) (Koster et al., 2011). Figure 12 compares this relationship before and after the mid-1990s for the central TP. The sensitivity of evaporation to SM change significantly increased after the wetting shift as the slope of the probability distribution increased substantially. In the arid and semi-arid climate dominated TP, the SM is relatively dry on average, and the evaporation is low. The limited SM cannot become too much lower during dry years. By contrast, it is more likely to produce impacts on evaporation and the overlying atmosphere through the surface energy budget during wet years. With the wetting shift in the mid-1990s, the SM seems to have entered a regime where it can have a significant impact on evaporation and the overlying atmosphere. 

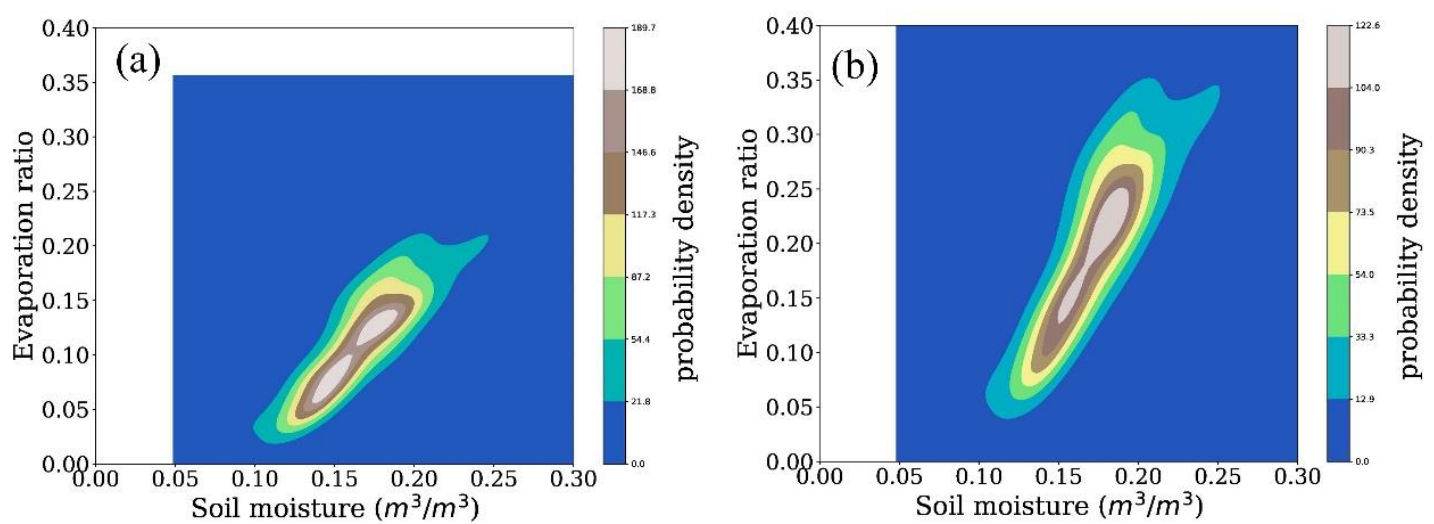

Figure 12. Probability distribution of the relationship between the evaporative ratio and the soil moisture in the stages of 1961-1994 (a) and 1995-2014 (b) for the central TP (the black rectangle region in Fig. 6).

SM regime changes may indicate a changing tendency of the climate system. The ratio of long-term average Prep to PET (Prep/PET, i.e., the Aridity index [AI]) provides a notable method of determining the climate regime of a region (Fu and Feng, 2014). The comparison of summer Prep/PET before and after the mid-1990s indicates an inclination of phase transition from a semi-arid to sub-humid, and a sub-humid to humid climate in summer over the semi-arid and sub-humid zones of the TP (Fig. S3) because the dividing lines for both expand to the northwest in the later stage (Fig. 13, 0.5 and 0.65 lines in the orange rectangle). The significance of this change can be reflected in the comparison of the statistics (mean, median, p25 and p75) from the grid-based summer Prep/PET with a varying Aridity index (Fig. S3) between the prior and later stages (Fig. 14). The overwhelmingly higher Prep/PET of the later stage (pink shaded area) than the prior for the semiarid and sub-humid zones (the area with AI in 0.2-0.65, Fig. S3) illustrates the evident wetting climate. The robust difference, particularly for the median and p75 statistics of Prep/PET at the upper critical point of the semi-arid (i.e., with the AI at 0.5) and sub-humid (i.e., with the $\mathrm{AI}$ at 0.65 ) climates, indicates the significance of the climate regime transition to a wetter summer over the semi-arid and sub-humid zone. The plateau enhances the Asian summer monsoon and modulates its variability by exerting strong thermal forcing on the mid-troposphere over the mid-latitude of the Northern Hemisphere during summer and spring (Yanai et al., 1992). The possible impacts of the abrupt wetting on Asia and even global climate via the strong land-atmosphere coupling over the transitional zone should also be attentioned. In addition, climate controls the structure and function of the ecosystem (Chen et al., 2013a). The large impact of the wetting climate transition on the original ecosystem must be considered, especially for parts of the TP with the most sensitive and fragile ecosystems. 


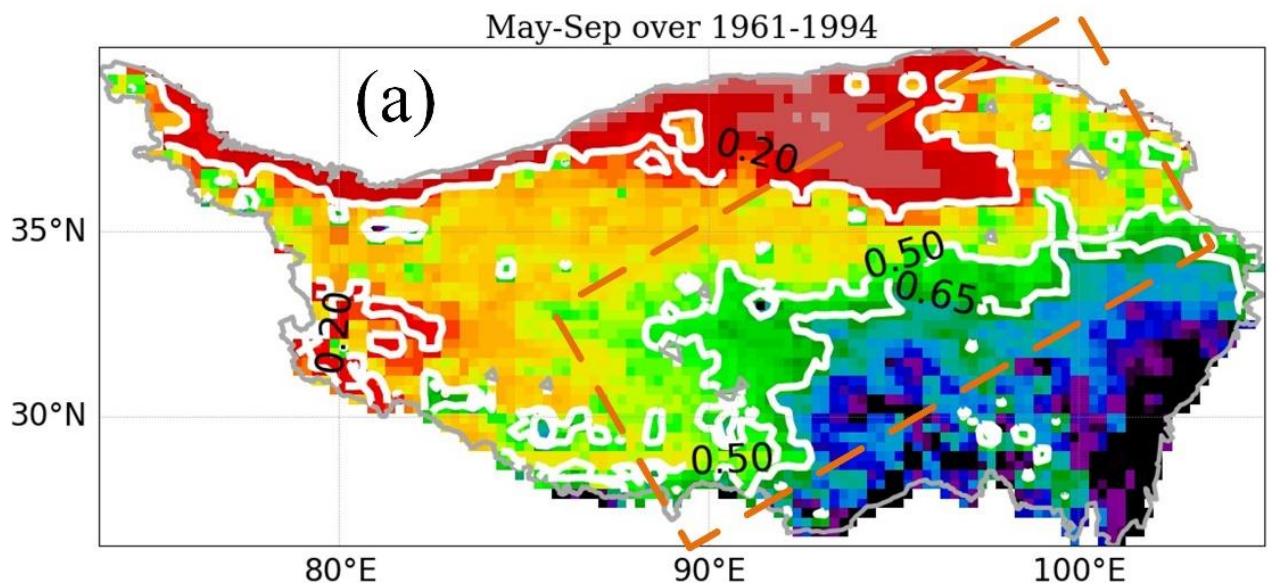

$-1.0$

0.8

$0.6 \frac{\text { ํํㅇ }}{0}$

0.4

$-0.2$

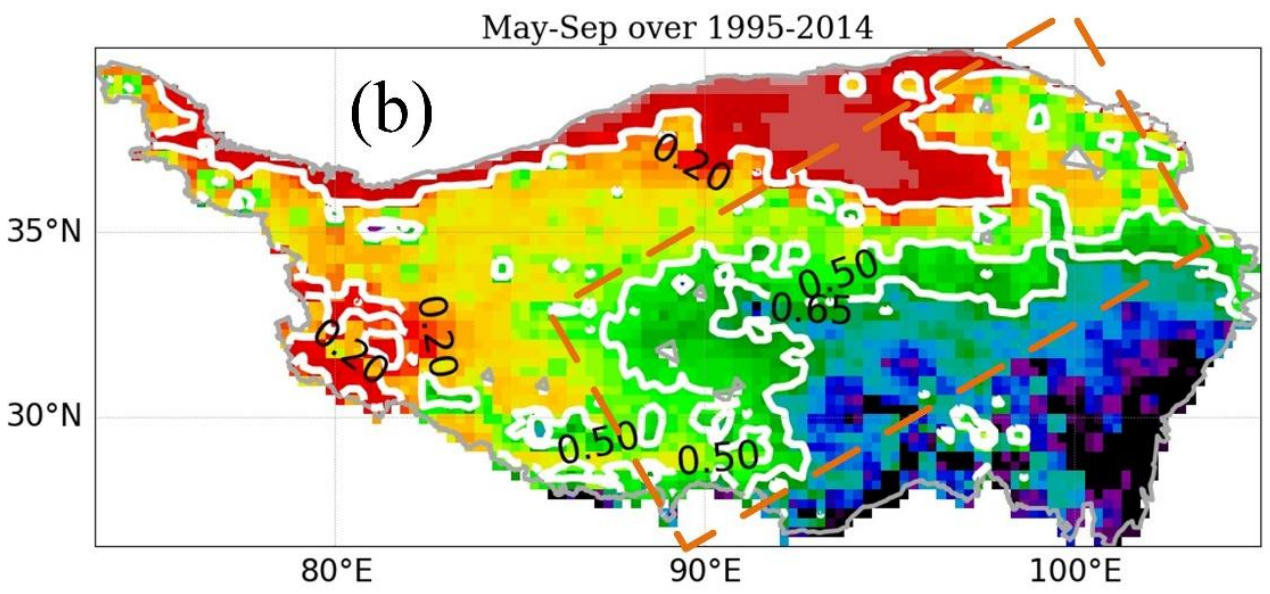

$-1.0$

$-0.8$

늘

Figure 13. Multi-year average Prep/PET for summer periods of May-September over the stages of 1961-1994 (a) and 1995-2014 (b). 

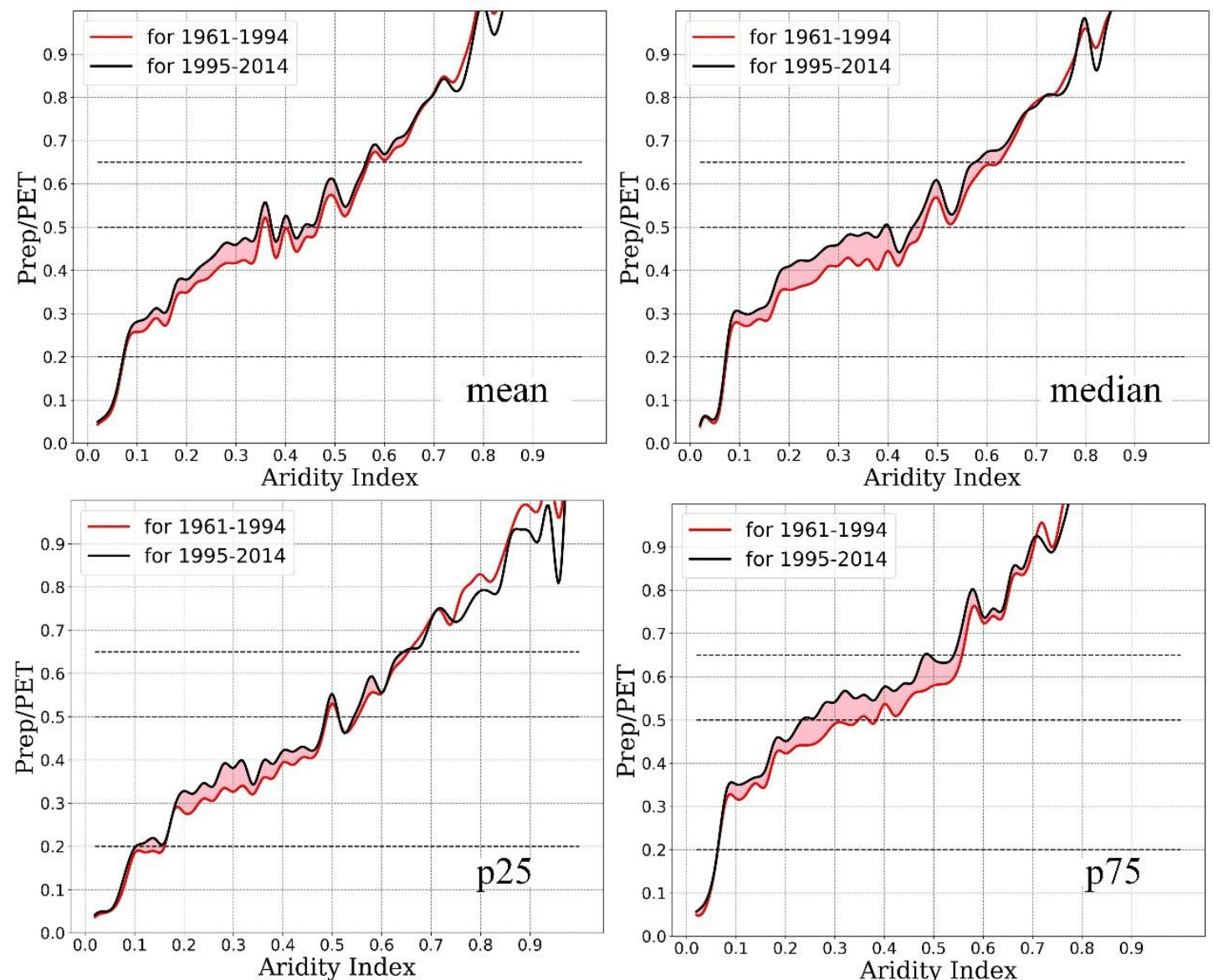

Figure 14. Variations of the Prep/PET statistics (mean, median, p25 and p75) over summer periods (May-September) with the Aridity index (AI, Figure S3) for both cases of 1961-1994 and 1995-2014. p25 and p75 are 25th and 75th quantile of the cumulative distribution of Prep/PET. The black dotted lines are the 0.2, 0.5 and 0.65 Prep/PET respectively. The pink shaded areas represent the degree of wetting shift after 1995.

\section{Conclusion}

This study explored the climate wetting/drying of the TP over the last half century from the variations of historical soil moisture SM droughts. The spatiotemporal patterns and long-term variations in summer (May-September) SM droughts and the climate causes were comprehensively investigated based on multi-source observation and reanalysis data.

As a result, 197 drought events (consisting of 350 drought clusters) were identified. Spatially, extensive regions, particularly for the central and southern TP endured long-lasting, comparatively severe, and frequent droughts. Large-scale drought clusters and severe droughts are mainly concentrated in semi-arid and sub-humid zones. The most severe drought 
event occurred in May 1994 and affected over $73 \%$ of the TP over 5 months' duration, driven by persistent, abnormally low Prep along with strong PET.

The TP experienced a significant phase shift of SM drought alleviation in the mid-1990s, indicating an abrupt hydroclimate shift to a wetter plateau. Drought alleviation occurred in $\sim 87 \%$ of the TP, with significant shifts in most of the central TP, particularly in the semi-arid and sub-humid regions. Before and after the phase shift, the drought tendency changed from a slight alleviating to an un-ignored enhancing trend for the entire TP. Spatially, the increasing trends in the southwest half and the decreasing trends in the northeast half of the plateau became more prominent after the mid-1990s.

We demonstrated that the shift alleviation of SM drought was predominately controlled by its dominant input (i.e., Prep), while its dominant output driver (i.e., PET) was only effective in the central-eastern TP. By contrast, the drought trends were likely predominantly driven by PET in the arid, semi-arid, and sub-humid climate-dominated plateau, particularly in west of $\sim 90^{\circ} \mathrm{E}$. The Prep driving forces appeared to be only effective in east of $\sim 90^{\circ} \mathrm{E}$. Furthermore, the Prep driving to the shift of SM drought can be largely attributed to the phase transition of the AMO from cold to warm accompanied by the weakening westerly since the mid-1990s and partly to the phase transition of PDO with the weakening ISM and EASM. The PET effects on the central-eastern wetting shift mainly benefitted from the abrupt decrease in wind speed over the TP. By contrast, the PET control on drought tendency was a combined effect of its climate-controlling factors of air temperature, solar radiation and vapor pressure deficit. The Prep impacts on trending are likely dominated by the weakening ISM under global warming.

415 Overall, with the objective of exploring the climate wetting/drying of the TP under the background of profound global climate change over the last half century, this study provides a comprehensive investigation on SM droughts in the TP. According to our review of the literature, the core variable of land-atmosphere water and energy cycle, that is SM, was first adopted as an indicator to characterize the drought and reflect the climate wetting/drying of the TP. A significant wetting shift in the plateau was observed. Furthermore, the wetting shift was interpreted synthetically from not only the dominant climate-controlling factors of SM but also the general circulation of the atmosphere. We demonstrated that the wetting shift indicated a SM regime change and an inclination of phase transition from semi-arid to sub-humid and sub-humid to humid climates. The large impact of the climate transition on the original sensitive and fragile ecosystem of the TP should be considered. The possible impacts of the overall wetting shift on global climate through the strong land-atmosphere coupling should also be attentioned. The aforementioned innovative work provides evidence for an abrupt wetting shift of the plateau over summer periods and is significant for further understanding climate change in the TP.

\section{Code and Data availability}

GLDASv2.0/Noah

dataset

is

available

from https://disc.gsfc.nasa.gov/datasets/GLDAS_NOAH025_M_2.0/summary?keywords=GLDAS. Precipitation and surface temperature data provided by the CMA are available at http://www.nmic.cn/data/cdcindex/cid/6d1b5efbdcbf9a58.html. The 
430 AMO indice is available at http://www.psl.noaa.gov/data/timeseries/AMO/, and the PDO indice is at https://www.ncdc.noaa.gov/teleconnections/pdo/. The ISM index is available from http://apdrc.soest.hawaii.edu/projects/monsoon/seasonal-monidx.html, and EASM index is from http://ljp.gcess.cn/dct/page/65540. The ERA5 dataset is available at https://cds.climate.copernicus.eu/cdsapp\#!/search?type=dataset. Further datasets and code can be accessed upon request

435 from the corresponding author.

\section{Author contributions}

Yongwei Liu and Yuanbo Liu conceived and designed the research. Yongwei Liu performed the experiments, wrote, and edited the paper. Wen Wang helped revised the paper. Han Zhou and Lide Tian gave constructive suggestions to improve the paper.

\section{Conflict of Interest statement}

The authors declare that they have no known competing financial interests or personal relationships that could have appeared to influence the work reported in this paper.

\section{Acknowledgements}

This work was supported by the Second Tibetan Plateau Scientific Expedition and Research Program 445 (2019QZKK0202), the National Natural Science Foundation of China (41901049, 41430855, 41961134003), Jiangsu Science and Technology Planning Youth Project (BK20191097) and National Key R\&D Program of China (2018YFE0105900).

\section{References}

Andreadis, K.M., Clark, E.A., Wood, A.W., Hamlet, A.F., and Lettenmaier, D.P.: Twentieth-century drought in the conterminous United States, J. Hydrometeorol., 6(6), 985-1001. https://doi.org/10.1175/Jhm450.1, 2005

Beaudoing, H. and M. Rodell, NASA/GSFC/HSL (2019), GLDAS Noah Land Surface Model L4 monthly 0.25 x 0.25 degree V2.0, Greenbelt, Maryland, USA, Goddard Earth Sciences Data and Information Services Center (GES DISC), Accessed: [Data Access Date], 10.5067/9SQ1B3ZXP2C5.

Bi, H., Ma, J., Zheng, W., and Zeng, J.: Comparison of soil moisture in GLDAS model simulations and in situ observations over the Tibetan Plateau, J. Geophys. Res.-Atmos., 121 (6), 2658-2678, https://doi.org/10.1002/2015JD024131, 2016. 
Chen, H., Zhu, Q., Peng, C., Wu, N., Wang, Y., Fang, X., Gao, Y., Zhu, D., Yang, G., Tian, J., Kang, X., Piao, S., Ouyang, H., Xiang, W., Luo, Z., Jiang, H., Song, X., Zhang, Y., Yu, G., Zhao, X., Gong, P., Yao, T., and Wu, J. H.: The impacts of climate change and human activities on biogeochemical cycles on the Qinghai-Tibetan Plateau, Glob. Change. Biol., 19, 2940-2955, https://doi.org/10.1111/gcb.12277, 2013a.

Chen, Y., Yang, K., Qin, J., Zhao, L., Tang, W., and Han, M.: Evaluation of AMSR-E retrievals and GLDAS simulations against observations of a soil moisture network on the central Tibetan Plateau, J. Geophys. Res.-Atmos, 118 (10), 4466-4475, https://doi.org/10.1002/jgrd.50301, 2013b.

Cheng, G., and Wu, T.: Responses of permafrost to climate change and their environmental significance, Qinghai-Tibet Plateau. J. Geophys. Res.,112, F02S03, https://doi.org/10.1029/2006JF000631, 2007.

Cuo, L., Zhang, Y., Zhu, F., and Liang, L.: Characteristics and changes of streamflow on the Tibetan Plateau: A review. J. Hydrol.: Reg. Stud., 2, 49-68,https://doi.org/10.1016/j.ejrh.2014.08.004, 2014.

Diro, G.T. and Sushama, L.: The role of soil moisture-atmosphere interaction on future hot-spells over North America as simulated by the Canadian Regional Climate Model (CRCM5), J. Clim., 30, 5041-5058, https://doi.org/10.1175/JCLID-16-0068.1., 2017.

Duan, A., and Xiao, Z.: Does the climate warming hiatus exist over the Tibetan Plateau? Sci. Rep., 5,13711, https://doi.org/10.1038/srep13711, 2015.

Fu, Q., and Feng, S.: Responses of terrestrial aridity to global warming, J. Geophys. Res.-Atmos.,119, 7863-75, https://doi.org/10.1002/2014JD021608, 2014.

Gao, G., Chen, D. Xu C.Y. and Simelton, E.: Trend of estimated actual evapotranspiration over China during 1960-2002, J. Geophys. Res. -Atmos., 112, D11120, https://doi.org/10.1029/2006JD008010, 2007.

Gao, Y., Cuo, L. and Zhang, Y.: Changes in moisture flux over the Tibetan Plateau during 1979-2011 and possible mechanisms, J. Clim., 27, 1876-1893. https://doi.org/ 10.1175/Jcli-D-13-00321.1, 2014.

Guttman, N.B.: Accepting the standardized precipitation index: A calculation algorithm, J. Am. Water Resour. Assoc., 35, 311-322, https://doi.org/10.1111/j.1752-1688.1999.tb03592.x,1999.

Herrera-Estrada, J.E., Satoh, Y., and Sheffield, J.: SpatioTemporal dynamics of global drought, Geophys. Res. Lett., 44 (5), 2254-2263, https://doi.org/10.1002/2016GL071768, 2017.

Koster, R.D., Chang, Y., Wang, H., and Schubert, S.D.: Impacts of Local Soil Moisture Anomalies on the Atmospheric Circulation and on Remote Surface Meteorological Fields during Boreal Summer: A Comprehensive Analysis over North America, J. Clim., 29(20), 7345-7364, https://doi.org/10.1175/jcli-d-16-0192.1, 2016.

485 Koster, R D., Mahanama, S. P. P., Yamada, T. J., Balsamo, G., Berg, A. A., Boisserie, M., Dirmeyer, P. A., Doblas-Reyes, F. J., Drewitt, G., Gordon, C. T., Guo, Z., Jeong, J. H., Lee, W. S., Li, Z., Luo, L., Malyshev, S., Merryfield, W. J., Seneviratne, S. I., Stanelle, T., van den Hurk, B. J. J. M., Vitart, F., Wood, E. F.: The Second Phase of the Global LandAtmosphere Coupling Experiment: Soil Moisture Contributions to Subseasonal Forecast Skill, J. Hydrometeorol., 12(5), 805-822, https://doi.org/10.1175/2011jhm1365.1, 2011. 
Kuang, X., and Jiao, J.J.: Review on climate change on the Tibetan Plateau during the last half century, J. Geophys. Res. Atmos., 121: 3979-4007, https://doi.org/ 10.1002/2015jd024728, 2016.

Lansu, E.M., van Heerwaarden, C.C., Stegehuis, A.I. and Teuling, A.J.: Atmospheric Aridity and Apparent Soil Moisture Drought in European Forest During Heat Waves, Geophys. Res. Lett., 47, 8, https://doi.org/10.1029/2020GL087091, 2020.

Li, H., Dai, A., Zhou, T., and Lu, J.: Responses of East Asian summer monsoon to historical SST and atmospheric forcing during 1950-2000, Climate Dyn., 34, 501-514, https://doi.org/10.1007/s00382-008-0482-7, 2010.

Li, J., and Zeng, Q.: A unified monsoon index, Geophys Res. Lett., 29(8), 4, https://doi.org/10.1029/2001GL013874, 2002.

Li, Y., Liao, J., Guo, H., Liu, Z., and Shen, G.: Patterns and potential drivers of dramatic changes in Tibetan lakes, 19722010, PLoS. One, 9(11), e111890, https://doi.org/10.1371/journal.pone.0111890, 2014.

Liu, X., and Chen, B.: Climatic warming in the Tibetan Plateau during recent decades, Int. J. Climatol., 20(14), 1729-1742, https://doi.org/10.1002/1097-0088[20001130]20:14<1729::AID-JOC556>3.0.CO;2-Y., 2000.

Liu, Y., Liu, Y., and Wang, W.: Inter-comparison of satellite-retrieved and Global Land Data Assimilation System-simulated soil moisture datasets for global drought analysis, Remote Sens. Environ., 220, 1-18, https://doi.org/ 10.1016/j.rse.2018.10.026, 2019a.

Liu, Y., Liu, Y., Wang, W. and Zhou, H.: Propagation of soil moisture droughts in a hotspot region: Spatial patternand Temporal trajectory, J. Hydrol., 593, 125906, https://doi.org/10.1016/j.jhydrol.2020.125906, 2021.

Liu, Y., Zhu, Y., Ren, L., Singh, V. P., Yong, B., Jiang, S., Yang, X.: Understanding the SpatioTemporal Links Between Meteorological and Hydrological Droughts From a Three-Dimensional Perspective. J. Geophys. Res. Atmos., 124(6), 3090-3109. https://doi.org/10.1029/2018JD028947,2019b.

Lloyd-Hughes, B.: A spatio-Temporal structure-based approach to drought characterisation: a structure-based approach to drought characterization, Int. J.Climatol., 32 (3), 406-418, https://doi.org/10.1002/joc.2280, 2012.

Pettitt, A.: A nonparametric approach to the change-point problem, Appl. Stat., 28:126-135, 1979.

Seneviratne, S.I., Corti, T., Davin, E.L., Hirschi, M., Jaeger, E.B., Lehner, I., Orlowsky, B., and Teuling, A.J.: Investigating soil moisture-climate interactions in a changing climate: A review, Earth Sci. Rev., 99,125-161, https://doi.org/ 10.1016/j.earscirev.2010.02.004, 2010.

Sheffield, J., Goteti, G., Wood, E.F., 2006. Development of a 50-year high-resolution global dataset of meteorological forcings for land surface modeling. J Clim., 19(13), 3088-3111, doi: 10.1175/JCLI3790.1.

Su, Z., Wen, J., Dente, L., Velde, R., Wang, L., Ma, Y., Yang, K., and Hu, Z.: The Tibetan Plateau observatory of plateau scale soil moisture and soil Temperature (Tibet-Obs) for quantifying uncertainties in coarse resolution satellite and model products, Hydrol. Earth Syst. Sci., 15 (7), 2303-2316, https://doi.org/10.5194/hess-15-2303-2011, 2011.

Sun, J., Yang, K., and Guo, W.: Why Has the Inner Tibetan Plateau Become Wetter since the Mid-1990s?, J. Climate., 33, 8507-8522, https://doi.org/10.1175/Jcli-D-19-0471.1, 2020. 
Tallaksen, L.M., Van Lanen, H.A.J., eds.: Hydrological drought: processes and estimation methods for streamflow and groundwater, Developments in water science; 48, Elsevier Science B.V., Amsterdam, the Netherlands, 2004.

Teng, H.F., Luo, Z.K., Chang, J.F., Shi, Z., Chen, S.C., Zhou, Y., Ciais, P., and Tian, H.Q.: Climate change-induced greening on the Tibetan Plateau modulated by mountainous characteristics. Environ. Res. Lett., 16(6), https://doi.org/ 10.1088/1748-9326/abfeeb, 2021.

Taylor, K.E., Stouffer, R.J., and Meehl, G.A.: An overview of CMIP5 and the experiment design, Bull. Am. Meteorol. Soc., 93 (4), 485-498, https://doi.org/10.1175/BAMS-D-11-00094.1, 2012.

530 Van Loon, A., and Van Lanen H.: A process-based typology of hydrological drought. Hydrol. Earth Syst. Sci., 16(7), 1915, https://doi.org/10.5194/hess-16-1915-2012, 2012.

Wan, W., Long, D., Hong, Y., Ma, Y., Yuan, Y., Xiao, P., Duan, H., Han, Z., and Gu, X.: A lake data set for the Tibetan Plateau from the 1960s, 2005, and 2014, Scientific Data, 3, 160039, https://doi.org/ 10.1038/sdata.2016.39, 2016.

Wanders, N., Bierkens, M.F.P., Jong, S.M., Roo, A., and Karssenberg, D.: The benefits of using remotely sensed soil moisture in parameter identification of large-scale hydrological models, Water Resour. Res., 50 (8), 6874-6891, https://doi.org/10.1002/2013WR014639, 2014.

Wang, B., Wu, R., Lau, K.M.: Interannual variability of Asian summer monsoon: Contrast between the Indian and western North Pacific-East Asian monsoons, J. Climate, 14, 4073-4090, https://doi.org/10.1175/15200442(2001)014<4073:IVOTAS>2.0.CO;2, 2001.

540 Wang, B., Q. Bao, Hoskins, B.,Wu, G., Liu, Y.: Tibetan Plateau warming and precipitation changes in East Asia, Geophys. Res. Lett., 35, L14702, https://doi.org/10.1029/2008GL034330, 2008.

Wang, T., Miao, J., Sun, J., and Fu, Y.: Intensified East Asian summer monsoon and associated precipitation mode shift under the $1.5 \quad{ }^{\circ} \mathrm{C}$ global warming target, Adv. Climate Change Res., 9, 102-111, https://doi.org/10.1016/j.accre.2017.12.002, 2018.

545 Wang, Z., Duan, A., Yang, S., and Ullah, K.: Atmospheric moisture budget and its regulation on the variability of summer precipitation over the Tibetan Plateau, J. Geophys Res. Atmos., 122(2), 614-630,https://doi.org/10.1002/2016JD025515, 2017.

Xie, H., Ye, J. Liu, X., and E, C.: Warming and drying trends on the Tibetan Plateau (1971-2005), Theor. Appl. Climatol., 101, 241-253, https://doi.org/10.1007/s00704-009-0215-9, 2010.

550 Xie, H., and Zhu, X.: Reference evapotranspiration trends and their sensitivity to climatic change on the Tibetan Plateau (1970-2009), Hydrol. Process, 27, 3685-3693, https://doi.org/10.1002/hyp.9487, 2013.

Xu, K., Yang, D., Yang, H., Li, Z., Qin, Y., and Shen, Y.: Spatio-Temporal variation of drought in China during 1961-2012: A climatic perspective, J. Hydrol., 526,253-264, https://doi.org/10.1016/j.jhydrol.2014.09.047, 2015.

$\mathrm{Xu}, \mathrm{Z}$. , Gong, T. and Li, J.: Decadal trend of climate in the Tibetan Plateau-regional Temperature and precipitation, Hydrol. Process, 22, 3056-3065, https://doi.org/10.1002/hyp.6892, 2008. 
Xue, Y.K., Ma, Y., and Li, Q.: Land-climate interaction over the Tibetan Plateau. Oxford Research Encyclopedia of Climate Science, https://doi.org/10.1093/acrefore/9780190228620.013.592,2017.

Yanai, M., Li, C., and Song, Z.: Seasonal heating of the Tibetan Plateau and its effects on the evolution of the Asian summer monsoon, J. Meteorol. Soc. Jpn, 70, 319-351, https://doi.org/10.2151/jmsj1965.70.1B_319,1992.

Yang, K., Ye, B. Zhou, D., Wu, B., Foken, T., Qin, J., and Zhou, Z.: Response of hydrological cycle to recent climate changes in the Tibetan Plateau, Clim. Change,109, 517-534, https://doi.org/10.1007/s10584-011-0099-4, 2011.

Yang, K., Wu, H., Qin, J., Lin, C.,Tang, W., and Chen, Y.: Recent climate changes over the Tibetan Plateau and their impacts on energy and water cycle: A review, Global Planet. Change, 112, 79-91, https://doi.org/10.1016/j.gloplacha.2013.12.001, 2014.

Yin, Y., Wu, S., Zhao, D., Zheng, D., and Pan, T.: Modeled effects of climate change on actual evapotranspiration in different eco-geographical regions in the Tibetan Plateau, J. Geogr. Sci., 23(2), 195-207, https://doi.org/10.1007/s11442-013-1003-0, 2013.

Yao, T., Thompson, L., Yang, W., Yu, W., Gao, Y., Guo, X., Yang, X., Duan, K., Zhao, H., Xu, B., Pu, J., Lu, A., Xiang, Y., Kattel, D., and Joswiak, D.: Different glacier status with atmospheric circulations in Tibetan Plateau and surroundings, Nat. Clim. Change, 2, 663-667, https://doi.org/10.1038/nclimate1580, 2012.

Yao, T., Xue, Y., Chen, D., Chen, F., Thompson, L., Cui, P., \& Li, Q. (2019). Recent third pole's rapid warming accompanies cryospheric melt and water cycle intensification and interactions between monsoon and environment: Multidisciplinary approach with observations, modeling, and analysis. Bulletin of the American Meteorological Society, 100(3), 423-444. https://doi.org/10.1175/BAMS-D-17-0057.1

You, Q., Fraedrich, K., Min, J., Kang, S., Zhu, X., Pepin, N., and Zhang, L.: Observed surface wind speed in the Tibetan Plateau since 1980 and its physical causes, Int. J. Climatol., 34(9), 1873-1882, https://doi.org/10.1002/joc.3807, 2014.

You, Q., Min, J., Jiao, Y., Sillanpää, M., and Kang, S.: Observed trend of diurnal temperature range in the Tibetan Plateau in recent decades. Int. J. Climatol., 36, 2633-2643, https://doi.org/10.1002/joc.4517, 2016.

Zeng, J., Li, Z., Chen, Q., Bi, H., Qiu, J., and Zou, P.: Evaluation of remotely sensed and reanalysis soil moisture products over the Tibetan Plateau using in-situ observations, Remote Sens. Environ., 163, 91-110, https://doi.org/ 10.1016/j.rse.2015.03.008, 2015.

Zhang, C., Tang, Q., Chen, D., van der Ent, R., Liu, X., Li, W., Haile, G.G.: Moisture Source Changes Contributed to Different Precipitation Changes over the Northern and Southern Tibetan Plateau, J. Hydrometeorol., 20(2), 217-229, https://doi.org/ 10.1175/Jhm-D-18-0094.1, 2019b.

Zhang, D., Huang, J., Guan, X., and Chen, B.: Long-term trends of precipitable water and precipitation over the Tibetan Plateau derived from satellite and surface measurements, J. Quant. Spectros. Radiat. Transfer., 122, 64-71, https://doi.org/ 10.1016/j.jqsrt.2012.11.028, 2013a.

Zhang, L., and Zhou, T.: Drought over East Asia: A Review, J. Climate, 28(8), 3375-3399, https://doi.org/10.1175/Jcli-D14-00259.1, 2015. 
590 Zhang, Q., Fan, K., and Singh V.P.: Is Himalayan-Tibetan Plateau "drying"? Historical estimations and future trends of surface soil moisture, Sci. Tot. Environ., 658, 374-384, https://doi.org/10.1016/j.scitotenv.2018.12.209, 2019a.

Zhang, Q., Fan, K., Singh, V.P., Sun, P., and Shi, P.: Evaluation of remotely sensed and reanalysis soil moisture against in situ observations on the Himalayan-Tibetan plateau, J. Geophys. Res. -Atmos., 123, 7132-7148, https://doi.org/10.1029/2017jd027763, 2018.

595 Zhang, X., Ren, Y., Yin, Z., Lin, Z., and Zheng, D.: Spatial and temporal variation patterns of reference evapotranspiration across the Qinghai-Tibetan Plateau during 1971-2004, J. Geophys. Res. -Atmos., 114, D15105, http://dx.doi.org/10.1029/2009JD011753, 2009.

Zhou, C., Zhao, P., and Chen, J.: The Interdecadal Change of Summer Water Vapor over the Tibetan Plateau and Associated Mechanisms, J. Climate., 32, 4103-4119. http://dx.doi.org/10.1175/Jcli-D-18-0364.1, 2019.

600 Zhu, Y., Liu, Y., Wang, W., Vijay, P.S., Ma, X., and Yu, Z.: Three dimensional characterization of meteorological and hydrological droughts and their probabilistic links, J. Hydrol., 578, 124016. http://dx.doi.org/10.1016/j.jhydrol.2019.124016, 2019.

Zwieback, S., Paulik, C., and Wagner, W.: Frozen soil detection based on advanced scatterometer observations and air Temperature data as part of soil moisture retrieval, Remote. Sens., 7, 3206-3231, http://dx.doi.org/10.3390/rs70303206, 2015. 